\title{
Complex Dynamics of Slack Mooring System Under Wave and Wind Excitations
}

\author{
A. Umar ${ }^{1, *}$, T. K. Datta ${ }^{2}$ and S. Ahmad ${ }^{3}$ \\ ${ }^{1}$ Department of Civil Engineering and Architecture, College of Engineering, University of Bahrain, Bahrain \\ ${ }^{2}$ Department of Civil Engineering, Indian Institute of Technology, New Delhi-110016, India \\ ${ }^{3}$ Department of Applied Mechanics, Indian Institute of Technology, New Delhi-110016, India
}

\begin{abstract}
In the present study, stability analysis of a multi-point slack moored buoy is performed under the action of wave and wind forces. The effect of non-linearities due to hydrodynamic damping, geometric nonlinearity due to mooring lines, nonlinearity due to restoring force and excitation force have been considered.. The dynamic analysis is done using time domain integration scheme. The wave force has been calculated using the Eatock Taylor and Hung's approach while the fluctuating wind force has been considered as a sinusoidally varying force the amplitude of which has been obtained in conjunction with IS:875-1987 (Part 3) Code. The approximate response of the system is determined by a two term harmonic balance method [1]. The stability analysis of the approximate solution is then performed using perturbation technique coupled with Hill's variational equation and Floquet's theory and the frequency ranges in which instability phenomena can occur are derived. Phase plots are obtained for finding bifurcation of solution like symmetry breaking bifurcation, period doubling bifurcation etc. Results are presented which illustrate the effects of the geometric nonlinearity of the mooring lines on the response of the buoy.
\end{abstract}

Keywords: Moored buoy, offshore structures, nonlinear response, first and second order wave forces, stability analysis.

\section{INTRODUCTION}

Ocean mooring systems include both single and multi point mooring systems. Multi-point mooring systems or spread mooring systems exhibit nonlinear behavior because of inherent nonlinearities in the system. These nonlinearities are produced either due to damping nonlinearity or due to nonlinearity in the restoring force or due to nonlinear excitation force or any combination of these. Amongst them, the nonlinearity of the restoring force generally leads to complex response behavior of the moored structure. The reason for the nonlinear restoring forces is the geometric nonlinearity or the catenary's effect of the mooring lines. As the moored vessel undergoes large excitation due to a combination of wave, wind and current, some of the mooring lines slacken and others become taut, thus providing a net nonlinear restoring force to the vessel.

The geometric nonlinearity of the mooring lines not only makes the problem nonlinear but may also lead to conditions of sub harmonic and super harmonic resonances, bifurcation of solutions and sensitivity to initial conditions. Therefore, the study of the response behaviour of the moored vessel needs a careful consideration of the consequences of the above factors. Phase plots are extensively used for finding bifurcation of solution like symmetry breaking bifurcation, period doubling, etc.

*Address Correspondence to this author at the Department of Civil Engineering and Architecture, College of Engineering, University of Bahrain, Bahrain; E-mail: arshad_umar@rediffmail.com
A few studies have been carried out on the nonlinear analysis of moored vessels under both wave and wind excitations. [2] carried out a study on nonlinear dynamic analysis of a moored vessel under wave forces in regular sea. $[1,3]$ presented a methodology for carrying out stability analysis of compliant structures under wave forces. They duly considered diffraction effect in the analysis. [4] carried out reliability analysis of taut and flexible mooring lines against instability. [5] introduced a linear, frequency-domain method for dynamic analysis to calculate large motions of slender structures such as towing and mooring cables and flexible risers. [6] studied the dynamic behaviour of tension leg platforms (TLP's) under the simultaneous action of random wind and wave fields. [7] carried out dynamic analysis of compliant offshore structures under wave and wind excitations. [8] presented the state of art review of the compliant structures. [9] derived three theories of the lowfrequency dynamics of ships and disks moored with multileg mooring systems in deep water. [10] carried out the analysis of offshore guyed tower platforms to wind and forces. The response analysis was performed by iterative frequency domain procedure. For obtaining the time histories of the wind velocity and water particle kinematics from their respective spectrums, Monte Carlo Simulation procedure was used. [11] studied the dynamic response of Tension Leg Platform in time domain to investigate the influence of nonlinearities due to hydro-dynamic drag force, variable cable submergence, long excursions and fluctuating wind together with the effect of coupling. Fluctuating wind was estimated using Emil Simiu's wind spectrum for compliant 
offshore structures. Random wind and wave were were modelled by Monte Carlo simulation.

Although the above studies provide a good understanding of the nonlinear behaviour of moored vessel under different conditions of excitations, there are certain areas where more work is needed. One such area is the stability analysis of the moored vessel under the action of wave and wind forces. Therefore, in the present study, a methodology for the stability analysis is presented and then stability analysis of a moored buoy is carried out.

\section{FORMULATION}

Following assumptions and simplifications are made:

(1) Sea waves are considered as regular sine waves.

(2) Wind force is considered as a sinusoidally varying force.

(3) Frequency of wave force and wind force is same.

(4) The mooring system is a single degree of freedom system.

(5) Motion of vessel is in surge (uncoupled) direction only.

(6) The restoring force determined is approximated by a $5^{\text {th }}$ order anti-symmetric polynomial.

\section{System Modeling}

To derive the equation of motion of the system shown in the Fig. (1), the equilibrium of the geometric restoring forces and small body motion under wave and wind excitation has been considered. The equation of motion is given as under

$M \ddot{x}+C \dot{x}+R(x)=F_{1} \sin (\omega t+\phi)$

Rearranging the equation of motion, Eq.1 yields the following first order autonomous equations.

$$
\begin{aligned}
& \ddot{x}+\lambda \dot{x}+r(x)=f_{1} \sin (\omega t+\phi) ; \quad \lambda=\frac{C}{M}, \quad f_{1}=\frac{F_{1}}{M} \\
& \text { and } r(x)=\frac{R(x)}{M} \\
& \dot{x}=y, \theta=\omega t+\phi, \quad \dot{y}=f_{1} \sin \theta-r(x)-\lambda y
\end{aligned}
$$

Where, $M$ is the system's mass including added mass; $C$ is the damping, which also includes the hydrodynamic damping; $R(x)$ is the displacement dependent non-linear restoring force; and $F_{1}$ is the amplitude of wave or the wind force.

The wave force is calculated using the Eatock Taylor and Hung's approach [1987]. Wind is essentially a random phenomenon. In the present study wind force amplitude is calculated in conjunction with IS:875-1987 (Part 3).

\section{Mooring Restoring Force $r(x)$}

For obtaining the total mooring restoring force, formulation given by Oppenheim and Wilson (1982) is used. A $5^{\text {th }}$ order antisymmetric polynomial is used to represent the restoring force $r(x)$ of the mooring system.
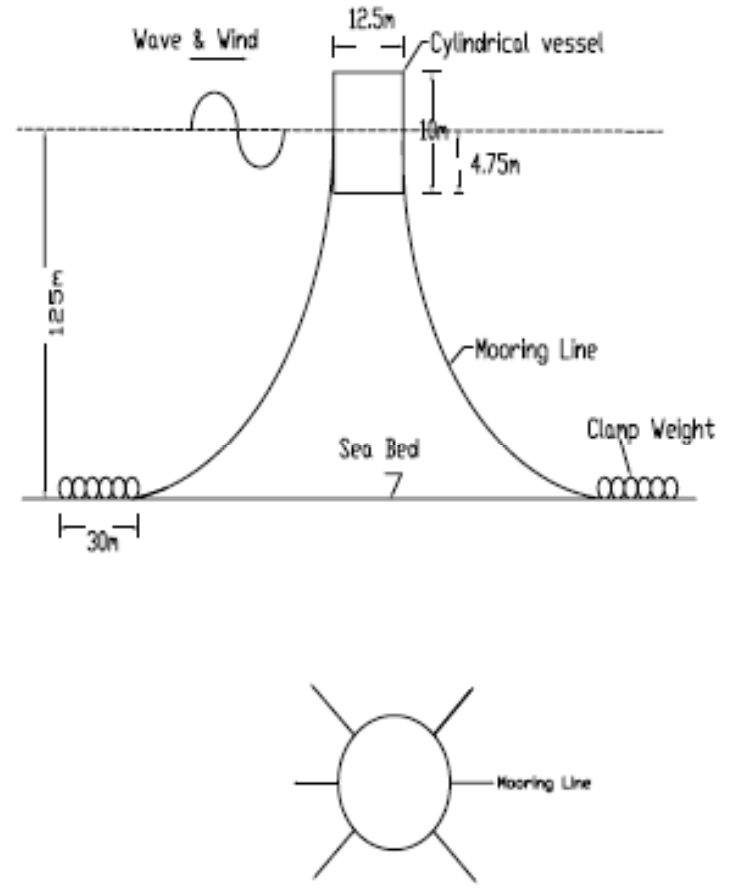

Fig. (1).

$r(x)=c_{1} x+c_{3} x^{3}+c_{5} x^{5}$

The coefficients of polynomial are obtained as

$\mathrm{c}_{1}=0.03100 \quad \mathrm{c}_{3}=-0.007864 \quad \mathrm{c}_{5}=0.004607$

The static force excursion relationship of the entire mooring system for the vessel is shown in Fig. (2). It is observed that antisymmetric polynomial closely describes the actual force displacement behaviour of the system.

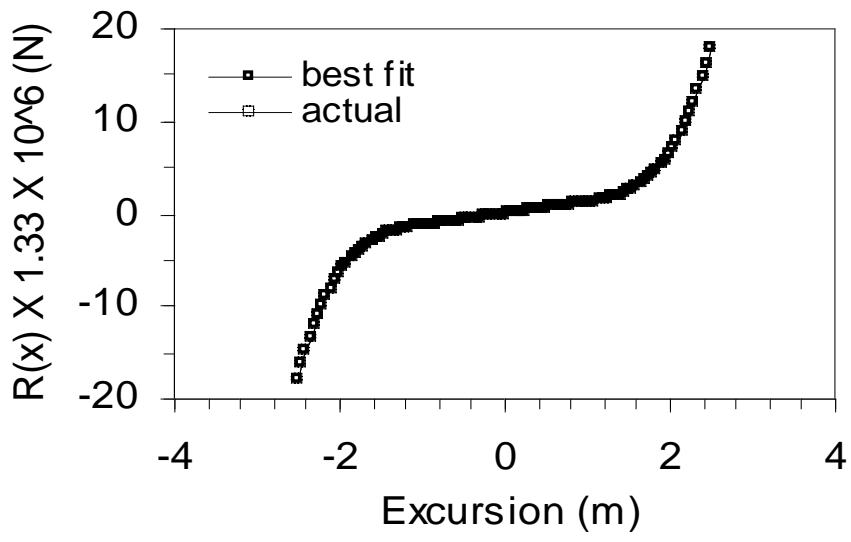

Fig. (2). Restoring force with excursion.

Approximate response of the system at different frequencies is obtained by solving Eq. (2) using Harmonic balance method (HBM). A two-term HBM solution is presented in the following section.

\section{HBM SOLUTION}

In the present study, approximate solution of equation of motion has been obtained by a well known Harmonic Balance Method (HBM). Considering two term solution for 
HBM, let the solution of the equation of motion Eq. (2) be given by

$$
\begin{aligned}
& x(t)=A_{1} \cos (\omega t+\phi)+A_{3} \cos (3 \omega t+\alpha) \\
& \dot{x}(t)=-\omega A_{1} \sin (\omega t+\phi)-3 \omega A_{3} \sin (3 \omega \mathrm{t}+\alpha) \\
& \ddot{x}(\mathrm{t})=-\omega^{2} A_{1} \cos (\omega \mathrm{t}+\phi)-9 \omega^{2} A_{3} \cos (3 \omega \mathrm{t}+\alpha)
\end{aligned}
$$

Substitution of $r(x), x, \dot{x}$, and $\ddot{x}$ etc. in $\mathrm{Eq}$ (1) and equating like terms on L.H.S and R.H.S of equation gives four sets of nonlinear equations with four unknowns i.e. $A_{l}$, $A_{3}, \alpha$ and $\phi$. . Solving the set of nonlinear equations (Appendix I) by iterative Newton Raphson method [1], the unknowns $A_{1}, A_{3}, \alpha$ and $\phi$ can be determined. Once these unknowns are obtained, the approximate response is given by Eq. (5) to Eq. (7)

\section{STABILITY ANALYSIS}

For a very strong nonlinear system under strong excitation, it is practically impossible to look into the problem of instability in totality. Examination of the subset of the problem is possible through analytical and numerical techniques. For not very strong nonlinear systems, various analytical methods have been forwarded for investigating these problems. For the mooring system, the nonlinearity mainly arises due to the geometric nonlinearity of the cables, which are the mooring lines. This geometric nonlinearity is neither very small nor it is too strong. Therefore, it may be possible to investigate the problem of instability of the mooring system by some analytical methods.

The proposed method consists of first finding the fixed points for the equation of motion without excitation. Then the limit cycle response of the system under forced condition is established and the global stability of the system is performed. The approximate response of the system is obtained by the harmonic balance method. Stability analysis of the approximate solution is then obtained using perturbation technique coupled with Hill's variational equation and Floquet's theory.

\section{GLOBAL STABILITY OF THE SYSTEM}

The potential energy $P(x)$ of the system is given by

$$
\begin{aligned}
P(x) & =\int r(x) d x \\
& =\int\left(c_{1} x+c_{3} x^{3}+c_{5} x^{5}\right) d x \\
P(x) & =\frac{c_{1} x^{2}}{2}+\frac{c_{3} x^{4}}{4}+\frac{c_{5} x^{6}}{6}+C^{\prime}
\end{aligned}
$$

where $C^{\prime}$ is a constant

The Hamiltonian energy $H(x, y)$ is given by

$$
H(x, y)=\frac{y^{2}}{2}+P(x)
$$

in which $y=\dot{x}$ as defined before.

Since the Hamiltonian is invariant for the autonomous system represented by Eq. (2), it is possible to write

$$
\frac{y^{2}}{2}+P(x)=P\left(x_{0}\right)
$$

in which $P\left(x_{0}\right)$ is a function of the initial condition. From Eq. (11), it follows that

$$
y=\sqrt{\left.2\left[P\left(x_{0}\right)\right]-P(x)\right]}
$$

Eq. (12) shows that the system has phase diagram with stable centres in two-dimentional space, although it does not have any fixed point in three-dimentional space $(x, y, \theta)$.

Local stability analysis of the unforced linearized system yields a unique asymptotically stable sink since eigenvalues of the linearized system have negative real parts.

$$
\text { i.e., } \gamma_{1,2}=\frac{-\lambda \pm \sqrt{\lambda^{2}-4 \alpha}}{2}
$$

in which the linearized unforced equation is given by

$$
\ddot{x}+\lambda \dot{x}+c_{1} x=0
$$

where $\lambda=\frac{C}{M} \quad$ and $\quad \alpha=c_{1}$

If the eigenvalues given by Eq. (13) are complex, then the sink is called a stable focus.

For the forced system with small harmonic wave excitation, the limit cycle motion about the fixed point is anticipated. The global stability of the system is performed by Liapunov function approach.

For the undamped Hamiltonian system, a weak Liapunov function may be considered by subtracting the constant term $C^{\prime}$ to the Hamiltonian energy given by Eq. (10).

$$
V(x, y)=\frac{y^{2}}{2}+P(x)-C^{\prime}
$$

From Eqs. (9) and (14), $V(0,0)=0$

Differentiating $V(x, y)$ with respect to $t$, we obtain the following nonlinear differential equation.

$$
\begin{aligned}
& \frac{d V}{d t}=y \dot{y}+\frac{d P(x)}{d t} \\
& \text { Therefore, } \frac{d V(0,0)}{d t}=0 \text { or } \quad \dot{V}(0,0)=0
\end{aligned}
$$

Since $V(0,0)$ and $\dot{V}(0,0)$ are zero, therefore the origin is neutrally stable.

If damping is accounted for, then a strong Liapunov function is found as

$$
V(x, y)=\frac{y^{2}}{2}+\left[P(x)-C^{\prime}\right]+v\left(x y+\frac{\lambda x^{2}}{2}\right)
$$

Where $v$ is the small constant multiplier

$$
\dot{V}(x, y)=y \dot{y}+r(x) \dot{x}+v[\dot{x} y+x \dot{y}+\lambda x \dot{x}]
$$


Since the system is unforced, from Eq. (2)

$$
\dot{y}=-r(x)-\lambda y
$$

Substituting $\dot{y}$ from Eq. (19) in Eq. (18)

$$
\begin{aligned}
& \dot{V}(x, y)=y\{-r(x)-\lambda y\}+r(x) y+v\left[y^{2}+x\{-r(x)-\lambda y\}+\lambda x y\right] \\
& =-v x r(x)-(\lambda-v) y^{2}
\end{aligned}
$$

Choice of $v$ sufficiently small $(0<v<\delta)$ results in a global stable unforced system, where $V(x, y)$ is positive definite and $d V / d t \leq 0$.

For a forced system

$$
\dot{y}=f_{1} \sin \theta-r(x)-\lambda y
$$

Substituting the value of $\dot{y}$ in Eq. (18)

$$
\dot{V}(x, y)=y\left\{f_{1} \sin \theta-r(x)-\lambda y\right\}+
$$$$
r(x) y+v\left[y^{2}+x\left\{f_{1} \sin \theta-r(x)-\lambda y\right\}+\lambda x y\right]
$$

Simplifying Eq. (22)

$\dot{V}(x, y)=(y+v x) f_{1} \sin \theta-\operatorname{vxr}(x)-(\lambda-v) y^{2}$

$\dot{V}(x, y)$ is maximum when $\sin \theta=1$ and the absolute maximum value of $\dot{V}(x, y)$ is

$|\dot{V}(x, y)|_{\max }=-v x r(x)-(\lambda-v) y^{2}+\left|v f_{0} x\right|+\left|f_{0} y\right|+\left|v x f_{1}\right|+\left|y f_{1}\right|$

Therefore,

$$
\dot{V}(x, y)=(y+v x) f_{1} \sin \theta-v x r(x)-(\lambda-v) y^{2} \leq|\dot{V}(x, y)|_{\max }
$$

For small $f_{1}$ and in the neighbourhood of $(x, y)=(0,0)$, solution of the systems remains bounded $(d V / d t \leq 0)$ and the limit cycle is globally stable for small excitation. Strong excitation and coexistence of solutions are examined by local stability analysis.

\section{LOCAL STABILITY OF THE SYSTEM}

Let $x_{o}(t)$ be the approximate solution obtained by HBM. Local stability of the approximate solution is determined by considering a perturbed solution given by

$x(t)=x_{0}(t)+\varepsilon(t)$

Differentiating with respect to time

$$
\begin{aligned}
& \dot{x}(t)=\dot{x}_{0}(t)+\dot{\varepsilon}(t) \\
& \ddot{x}(t)=\ddot{x}_{0}(t)+\ddot{\varepsilon}(t) \\
& \text { Since } \dot{x}=y \\
& \ddot{x}_{0}(t)+\ddot{\varepsilon}(t)=f_{1} \sin \theta-r\left(x_{0}+\varepsilon\right)-\lambda \dot{x}_{0}(t)-\lambda \dot{\varepsilon}(t) \\
& \quad r\left(x_{0}+\varepsilon\right) \text { may be written as } \\
& r\left(x_{0}(t)+\varepsilon(t)\right)=c_{1}\left(x_{0}+\varepsilon\right)+c_{3}\left(x_{0}+\varepsilon\right)^{3}+c_{5}\left(x_{0}+\varepsilon\right)^{5}
\end{aligned}
$$

$$
\begin{aligned}
& =\left[c_{1} x_{0}+c_{3} x_{0}^{3}+c_{5} x_{0}^{5}\right]+c_{1} \varepsilon+c_{3} \varepsilon^{3}+3 c_{3} x_{0}^{2} \varepsilon+ \\
& 3 c_{3} x_{0} \varepsilon^{2}+c_{5} \varepsilon^{5}+5 c_{5} x_{0}^{4} \varepsilon+ \\
& \quad 10 c_{5} x_{0}^{3} \varepsilon^{2}+10 c_{5} x_{0}^{2} \varepsilon^{3}+5 c_{5} x_{0} \varepsilon^{4} \\
& =r\left(x_{0}\right)+c_{1} \varepsilon+c_{3} \varepsilon^{3}+3 c_{3} x_{0}^{2} \varepsilon+3 c_{3} x_{0} \varepsilon^{2}+c_{5} \varepsilon^{5}+ \\
& 5 c_{5} x_{0}^{4} \varepsilon+10 c_{5} x_{0}^{3} \varepsilon^{2}+ \\
& 10 c_{5} x_{0}^{2} \varepsilon^{3}+5 c_{5} x_{0} \varepsilon^{4}
\end{aligned}
$$

Substituting for $r\left(x_{0}+\varepsilon\right)$ and rearranging terms, Eq. (29) becomes

$$
\begin{aligned}
& \ddot{x}_{0}(t)-f_{1} \sin \theta+\lambda \dot{x}_{0}+r\left(x_{0}\right)+\ddot{\varepsilon}+\lambda \dot{\varepsilon}+\mathrm{c}_{1} \varepsilon+\mathrm{c}_{3} \varepsilon^{3} \\
& +3 \mathrm{c}_{3} x_{0}^{2} \varepsilon+3 \mathrm{c}_{3} x_{0} \varepsilon^{2}+\mathrm{c}_{5} \varepsilon^{5}+ \\
& 5 \mathrm{c}_{5} x_{0}^{4} \varepsilon+10 \mathrm{c}_{5} x_{0}^{3} \varepsilon^{2}+10 \mathrm{c}_{5} x_{0}^{2} \varepsilon^{3}+5 \mathrm{c}_{5} x_{0} \varepsilon^{4}=0
\end{aligned}
$$

From Eq. (2)

$$
\ddot{x}_{0}(t)-f_{1} \sin \theta+r\left(x_{0}\right)+\lambda \dot{x}_{0}(t)=0
$$

Therefore, Eq. (32) becomes

$\ddot{\varepsilon}+\lambda \dot{\varepsilon}+\mathrm{c}_{1} \varepsilon+\mathrm{c}_{3} \varepsilon^{3}+3 \mathrm{c}_{3} x_{0}^{2} \varepsilon+3 \mathrm{c}_{3} x_{0} \varepsilon^{2}+\mathrm{c}_{5} \varepsilon^{5}+5 \mathrm{c}_{5} x_{0}^{4} \varepsilon+$ $10 \mathrm{c}_{5} x_{0}^{3} \varepsilon^{2}+10 \mathrm{c}_{5} x_{0}^{2} \varepsilon^{3}+5 \mathrm{c}_{5} x_{0} \varepsilon^{4}=0$

Eq. (33) can be written as

$\ddot{\varepsilon}+\lambda \dot{\varepsilon}+\alpha G\left[\varepsilon, x_{0}\right]=0$

where

$$
\begin{aligned}
& G\left(\varepsilon, x_{0}\right)=\frac{1}{\alpha}\left[\mathrm{c}_{1} \varepsilon+\mathrm{c}_{3} \varepsilon^{3}+3 \mathrm{c}_{3} x_{0}^{2} \varepsilon+3 \mathrm{c}_{3} x_{0} \varepsilon^{2}+\right. \\
& \mathrm{c}_{5} \varepsilon^{5}+5 \mathrm{c}_{5} x_{0}^{4} \varepsilon+10 \mathrm{c}_{5} x_{0}^{3} \varepsilon^{2}+ \\
& \left.10 \mathrm{c}_{5} x_{0}^{2} \varepsilon^{3}+5 \mathrm{c}_{5} x_{0} \varepsilon^{4}\right]
\end{aligned}
$$

Linearizing the above variational equation yields a linear ordinary differential equation with a periodic coefficient $H\left[x_{0}(t)\right]=H\left[x_{0}(t+T)\right]$

$H\left[x_{0}(t)\right]$ is defined in the following manner.

Differentiating Eq. (35) with respect to $\varepsilon$.

$$
\begin{aligned}
& \frac{d G\left(\varepsilon, x_{0}\right)}{d \varepsilon}=\frac{1}{\alpha}\left[\mathrm{c}_{1}+3 \mathrm{c}_{3} \varepsilon^{2}+3 \mathrm{c}_{3} x_{0}^{2}+6 \mathrm{c}_{3} x_{0} \varepsilon+5 \mathrm{c}_{5} \varepsilon^{4}\right. \\
& \left.+5 c_{5} x_{0}^{4}+20 \mathrm{c}_{5} x_{0}^{3} \varepsilon+30 \mathrm{c}_{5} x_{0}^{2} \varepsilon^{2}+20 \mathrm{c}_{5} x_{0} \varepsilon^{3}\right]
\end{aligned}
$$

Therefore,

$$
\frac{d G\left(0, x_{0}\right)}{d \varepsilon}=\frac{1}{\alpha}\left[c_{1}+3 c_{3} x_{0}^{2}+5 c_{5} x_{0}^{4}\right]
$$

Expanding by Taylor series, $G\left(\varepsilon, x_{0}\right)$ may be written as 
Table 1. Numerical Data Used in the Study

\begin{tabular}{|c|c|}
\hline $\begin{array}{ll}\text { - } & \text { Buoy (dia,height,thickness) } \\
\text { - } & \text { Submerged depth of the buoy } \\
\text { - } & \text { Mass of the buoy } \\
\text { - } & \text { Total length of each mooring line } \\
\text { - } & \text { Mass of the mooring line in water } \\
\text { - } & \text { Young's modulus of mooring lines } \\
\text { - } & \text { Clamp length of the cable } \\
\text { - } & \text { Mass of the clamp in water } \\
\text { - } & \text { Specth of the sea } \\
\text { - } & \text { Initial angle of inclination } \\
\text { - } & \text { Initial horizontal tension } \\
\text { - } & \text { Structural damping } \\
& \text { Basic wind speed }\end{array}$ & $\begin{array}{l}12.5 \mathrm{~m} \times 10 \mathrm{mx} 0.3 \mathrm{~m} \\
4.75 \mathrm{~m} \\
275957.5 \mathrm{~kg} \\
6 \\
500 \mathrm{~m} \\
21 \mathrm{~kg} / \mathrm{m} \\
20.595 \times 10^{9} \mathrm{~N} / \mathrm{m}^{2} \\
30 \mathrm{~m} \\
90 \mathrm{~kg} / \mathrm{m} \\
125 \mathrm{~m} \\
\\
2.4 \\
60^{0} \\
19000 \mathrm{~N} \\
3.25 \% \\
44 \mathrm{~m} / \mathrm{s} \\
\end{array}$ \\
\hline
\end{tabular}

Table 2. Wave Forces

\begin{tabular}{|c|c|c|c|}
\hline Wave & $\begin{array}{c}\text { Primary Wave Force } \boldsymbol{F}^{(\mathbf{l})} \\
(\mathbf{N})\end{array}$ & $\begin{array}{c}\text { Second Order Oscillatory Wave Force } \\
\boldsymbol{F}_{\boldsymbol{o}}^{(2)}(\mathbf{N})\end{array}$ & $\begin{array}{c}\text { Total Second Order } \\
\text { Wave Force } \mathbf{F}^{(2)} \\
(\mathbf{N})\end{array}$ \\
\hline \hline $5 \mathrm{~m} / 5 \mathrm{~s}$ & 333581.8 & 16833.41 & 20834.79 \\
\hline $12 \mathrm{~m} / 10 \mathrm{~s}$ & 1467107.79 & 94929.38 & 14818.91 \\
\hline $18 \mathrm{~m} / 15 \mathrm{~s}$ & 2201669.68 & 22076.60 & 3366.68 \\
\hline
\end{tabular}

Table 3. Hydrodynamics

\begin{tabular}{|c|c|c|c|c|c|c|c|}
\hline Wave & $\begin{array}{c}\text { Added Mass } \\
\text { Coefficient } \\
\mathbf{c}_{\mathrm{mi}}\end{array}$ & $\begin{array}{c}\text { Hydrodynamic } \\
\text { Damping } \\
\text { Coefficient } \\
c_{d i}\end{array}$ & $\begin{array}{c}\text { Added Mass } \\
\mathbf{m}^{\prime} \\
(\mathbf{k g})\end{array}$ & $\begin{array}{c}\text { Hydrodynamic } \\
\text { Damping } \\
\mathbf{c}^{\prime} \\
\mathrm{N} /(\mathbf{m} / \mathbf{s})\end{array}$ & $\begin{array}{c}\text { Total } \\
\text { Damping } \\
\text { C N/(m/s) }\end{array}$ & $\begin{array}{c}\text { Total Mass } \\
\text { M } \\
(\mathbf{k g})\end{array}$ & $\lambda=\mathrm{C} / \mathrm{M}$ \\
\hline $5 \mathrm{~m} / 5 \mathrm{~s}$ & 0.253 & 0.130 & 151163.9 & 97604.09 & 100762.3 & 427121.44 & 0.2359 \\
\hline $12 \mathrm{~m} / 10 \mathrm{~s}$ & 0.2375 & 0.0225 & 141902.88 & 8446.51 & 11604.21 & 417860.38 & 0.02777 \\
\hline $18 \mathrm{~m} / 15 \mathrm{~s}$ & 0.226 & 0.02 & 135031.79 & 5004.54 & 8162.75 & 410989.30 & 0.01986 \\
\hline
\end{tabular}

$G\left(\varepsilon, x_{0}\right)=G\left(0, x_{0}\right)+\varepsilon G^{\prime}\left(0, x_{0}\right)$

where $G^{\prime}$ represents $\frac{d G\left(\varepsilon, x_{0}\right)}{d \varepsilon}$

Therefore, $G\left(\varepsilon, x_{0}\right)=0+\frac{\varepsilon}{\alpha}\left\{c_{1}+3 c_{3} x_{0}^{2}+5 c_{5} x_{0}^{4}\right\}$

Substituting for $G\left(\varepsilon, x_{0}\right)$ in Eq. (34)

$\ddot{\varepsilon}+\lambda \dot{\varepsilon}+\alpha H\left[x_{0}(t)\right] \varepsilon=0$

Where $H\left[x_{0}(t)\right]=\frac{1}{\alpha}\left[c_{1}+3 c_{3} x_{0}^{2}+5 c_{5} x_{0}^{4}\right]$

Expanding $H\left[x_{0}(t)\right]$ in a Fourier series $H(\bar{\theta})$, leads to a general Hill's variational equation [3].

$\ddot{\varepsilon}+\lambda \dot{\varepsilon}+\alpha H[\bar{\theta}(t)] \varepsilon=0$ where $H(\bar{\theta})=\frac{a_{0}}{2}+\sum_{n} a_{n} \cos n \bar{\theta}$ and

$\bar{\theta}(t)=\omega t+\phi+\Phi$

where $a_{n}=\frac{2}{\pi} \int_{0}^{\pi} H(\bar{\theta}) \cos (n \bar{\theta}) d \bar{\theta} ;$

$n=\left\{\begin{array}{lc}1,2,3, \ldots \ldots \ldots . . . & {[x(t)-\text { unsymmetric }]} \\ 2,4,6, \ldots \ldots . . . k & {[x(t)-\text { symmetric }]}\end{array}\right.$

The particular solution to the variational equation $\varepsilon=\exp (\xi t) Z(t)$ can be found by Floquet theory [13] with $Z(t)$ $=Z(t+T)$ and $Z(t)=Z(t+T / 2)$ for the symmetric solution. The unsymmetric solution results in non-zero odd harmonic components with a period doubled solution form $Z(t)=Z(t+$ $2 T)$ in Eq. (43)

The lowest order instability of the solution form $Z(t)=$ $Z(t+2 T)$ is obtained by inserting the period doubled $\varepsilon(t)=b_{1 / 2} \cos (\theta / 2)$ into Eq. (42). The boundaries of the unstable region are given by 
$\omega^{2}=2\left[\alpha a_{0}-\lambda^{2} \pm \sqrt{\lambda^{4}-2 \alpha \lambda^{2} a_{0}+\alpha^{2} a_{1}^{2}}\right]$

For the undamped system Eq. (46) simplifies to $\omega \approx \sqrt{2 \alpha a_{0}}$. Proof of Eq. 46 is given in Appendix II.

Symmetric solutions such as $x_{0}(t)=A_{1} \cos \theta$, do not exhibit a period doubling phenomenon $Z(t) \neq Z(t+2 T)$ but determine secondary resonances in which the $Z(t)=Z(t+$ $T / 2$ ). Such solution may be unstable and the instability is obtained by inserting the unsymmetric solution form $\varepsilon(t)=b_{0}+b_{2} \cos (2 \theta)$ into Eq. (42). The unstable super harmonic region is given by

$\omega^{2}=\frac{1}{8 a_{0}}\left[\alpha\left(a_{0}^{2}-a_{2}^{2}\right)-\lambda^{2} a_{0} \pm \sqrt{\lambda^{4} a_{0}^{2}+2 \alpha \lambda^{2}\left(a_{2}^{2}-a_{0}^{2}\right)+\alpha^{2}\left(a_{2}^{2}-2 a_{0} a_{4}\right)^{2}}\right]$

For the undamped system Eq. (47) simplifies to $\omega \approx \sqrt{\alpha a_{0} / 8}$. Eq. (47) may be derived in the same way as it is done for Eq. (46).

\section{DISCUSSION OF THE RESULTS}

Fig. (3) shows the variation of maximum response (amplitude, $A$ ) of the moored buoy with frequency $(\omega)$ for $f_{1}=2$ and $\lambda=0.02777$. The responses are obtained using (i) harmonic balance method (ii) Adam's integration scheme (with initial condition $x, y=0,0)$. For higher frequency $(\omega>$ $1.4 \mathrm{rad} / \mathrm{sec})$, the variation of response obtained by the two methods is the same. For $(\omega<1.4 \mathrm{rad} / \mathrm{sec})$, the amplitude of the response using harmonic balance method is smaller. As discussed earlier, the responses obtained by harmonic balance method are approximate. From the variation of response with frequency as obtained from the harmonic balance method, it is observed that the system shows some kind of instability for $0.35<\omega<0.83 \mathrm{rad} / \mathrm{sec}$. Time domain solution also indicates some kind of instability in this region. From Hill's equation, Eq. (47), the frequency range for which instability phenomenon are expected to occur is computed as 0.34 to $0.374 \mathrm{rad} / \mathrm{sec}$. For $\omega$ greater than 1.30 $\mathrm{rad} / \mathrm{sec}$, system is expected to experience no instability phenomenon.

For verifying the above, stability analysis has been carried out for three different regular sea-states namely (i) $5 \mathrm{~m} / 5 \mathrm{sec}$; (ii) $12 \mathrm{~m} / 10 \mathrm{sec}$; and (iii) $18 \mathrm{~m} / 15 \mathrm{sec}$. The wave periods are selected so that frequency of excitation lies in the range of 0.35 to $0.83 \mathrm{rad} / \mathrm{sec}$ i.e. periods ranging from 8 to $20 \mathrm{sec}$ in which instability phenomenon is expected to occur. Thus, regular sea states having periods $10 \mathrm{sec}$ and $15 \mathrm{sec}$ are expected to show some kind of instability. The numerical data, the wave forces and the hydrodynamics used in the study, are given in Tables $\mathbf{1}, \mathbf{2}$ and $\mathbf{3}$ respectively.

The response of the system is obtained in the time domain using Adam's time integration scheme. Time history of the responses and phase plots have been plotted for various forces. The system is stable if the time history of the response is periodic with the same time period as the excitation force and the system is not sensitive to initial conditions and the phase plot is symmetrical. Moreover, if the time history of the response is not periodic or periodic but the time period of the response is not same as excitation force and the phase plot is not symmetrical, then the system shows instability phenomenon. If the phase plots are not symmetric, then system shows symmetry breaking phenomenon. If the period of response is twice the period of excitation force, the system shows period doubling phenomenon.

\section{Responses Due to $5 \mathrm{~m} / 5 \mathrm{sec}$ Wave}

Figs. (4) and (5) show the response and phase plots respectively of the moored buoy for $5 \mathrm{~m} / 5 \mathrm{sec}$ wave due to first order wave force for the initial condition $(x, y=0,0)$. The steady state response is harmonic and phase plot is symmetrical. The maximum response is $0.32 \mathrm{~m}$. It was found that even for the changed initial condition $(x, y=1,1)$, the steady state response and the phase plots have not changed. Thus, it can be concluded that for $5 \mathrm{~m} / 5 \mathrm{sec}$ wave, the moored system does not show any stability problem under primary wave force.

Since the frequency of excitation is twice the frequency of the primary wave force, it is likely that the response of the moored system will not have any stability problem due to second order wave force. However, this is verified by examining the response and phase plots of the system.

Response and phase plots of the buoy, when subjected to second order force are shown in Figs. (6) and (7) respectively for the initial condition $(x, y=0,0)$. The response due to total second order forces is larger than the response due to the first order force. This is due to the steady component $\left(F_{\mathrm{m}}\right)$ of the force. The maximum response is $1.71 \mathrm{~m}$, while the maximum response due to primary wave force is $0.32 \mathrm{~m}$. Response and phase plots for the changed initial condition $(x, y=-1,0.5)$ were found to be identical to those found for the initial condition $(x, y=0,0)$ (Figs. 6 and 7) indicating that the system remains stable under total second order force.

The response and phase plots of the buoy when subjected to the total wave forces i.e. combination of first and second order wave forces are shown in Figs. (8) and (9) respectively for the initial condition $(x, y=0,0)$. From the Figs. (8) and (9), it is seen that the response is periodic and the phase plot is symmetrical. The maximum response is $2.03 \mathrm{~m}$. Phase

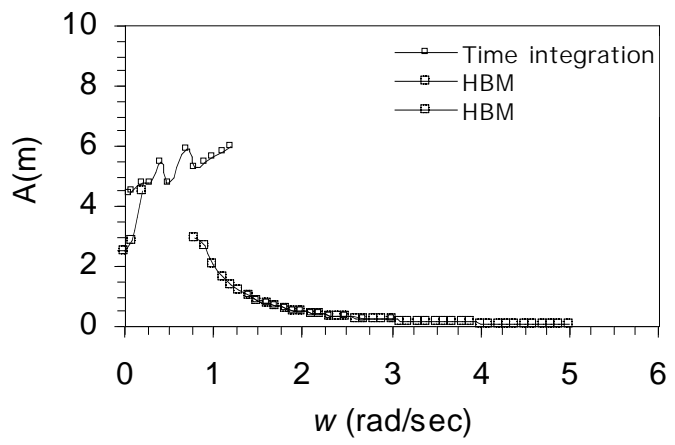

Fig. (3). Variation of maximum amplitude (A) with frequency of excitation. 


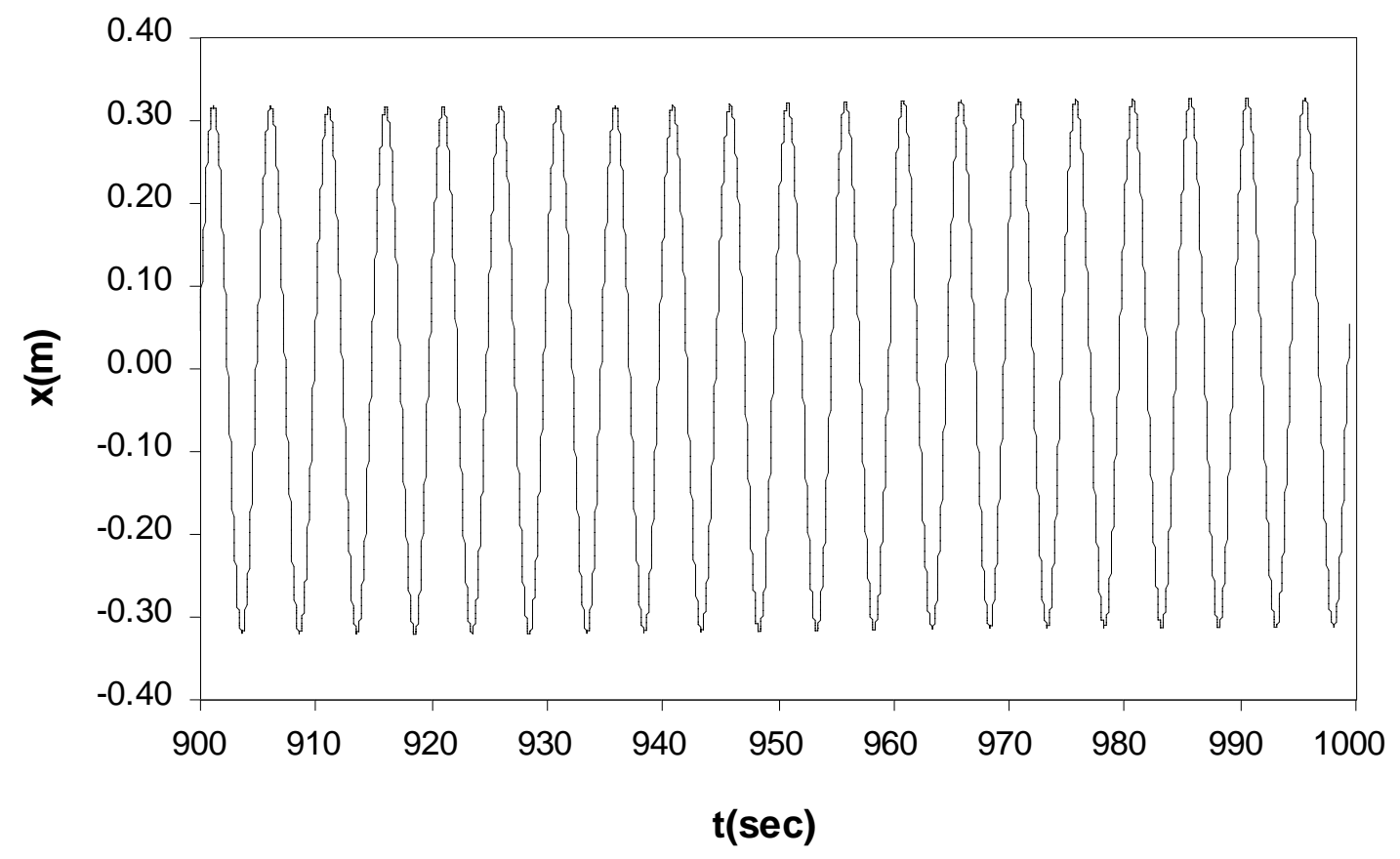

Fig. (4). Time history of the response $(x)$ due to primary wave force $[5 \mathrm{~m} / 5 \mathrm{~s}$ wave; $(x, y)=(0,0)]$.

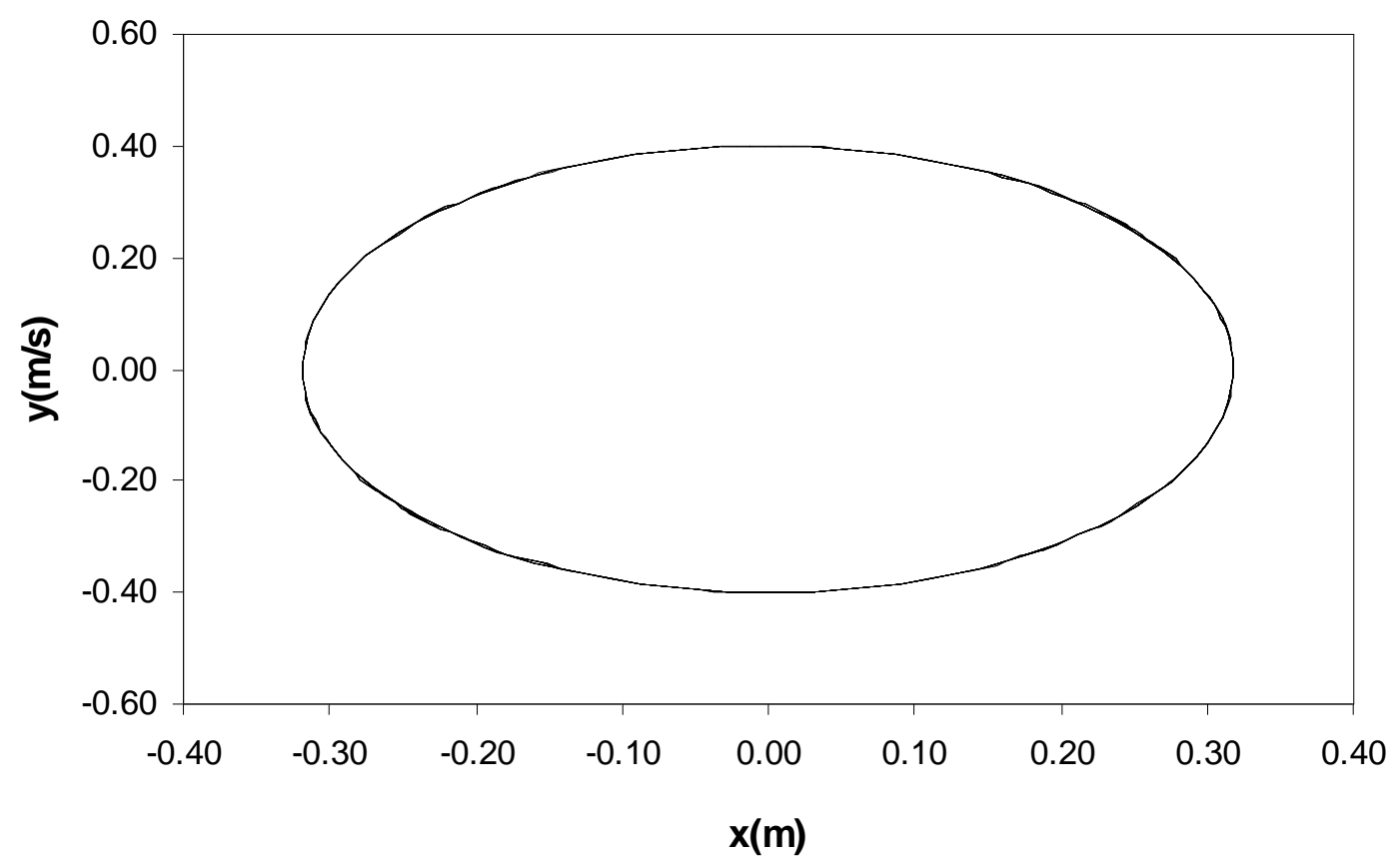

Fig. (5). Phase plot of the response $(x)$ due to primary wave force $[5 \mathrm{~m} / 5 \mathrm{~s}$ wave; $(x, y)=(0,0)]$.

plots for two other initial conditions $(x, y=1.0,1.0$ and $-1.0,0.50)$ are found to be identical.

\section{Response Under Wind Force}

The response and phase plots of the buoy when subjected to the wind force of frequency $1.2566 \mathrm{rad} / \mathrm{sec}$ are shown in Figs. (10) and (11) respectively for the initial condition $(x, y$ $=0,0)$. From the Figs. (11) and (12), it is seen that the response is periodic and the phase plot is symmetrical. The maximum response is $0.22 \mathrm{~m}$.

\section{Response Under the Combination of Wave and Wind Force}

The response and phase plots of the buoy when subjected to the combination of wave $(5 \mathrm{~m} / 5 \mathrm{sec}$ wave) and wind force are shown in Figs. (12 and 13) respectively for the initial condition $(x, y=0,0)$. From the Figs. (12 and 13), it is seen that the response is periodic and the phase plot is symmetrical. The maximum response is $2.25 \mathrm{~m}$. Thus, response is governed by wave forces. 


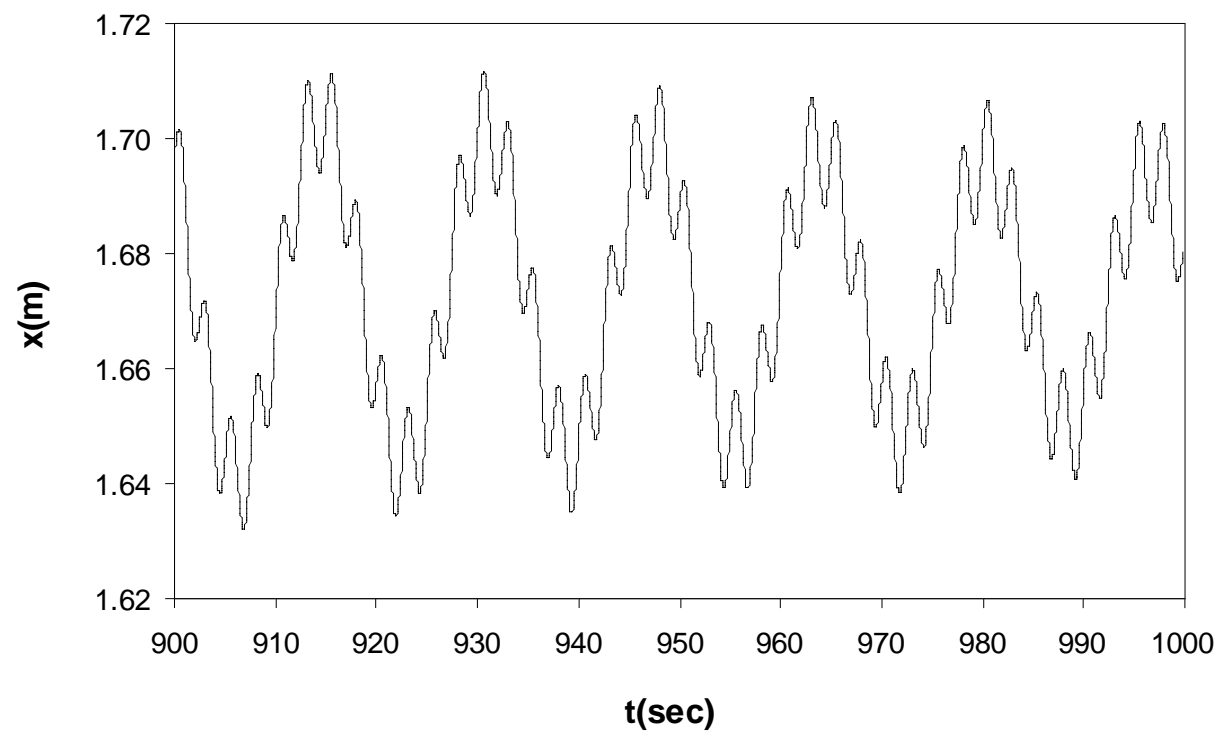

Fig. (6). Time history of the response (x) due to total second order wave force $[5 \mathrm{~m} / 5 \mathrm{~s}$ wave; $(x, y)=(0,0)]$.

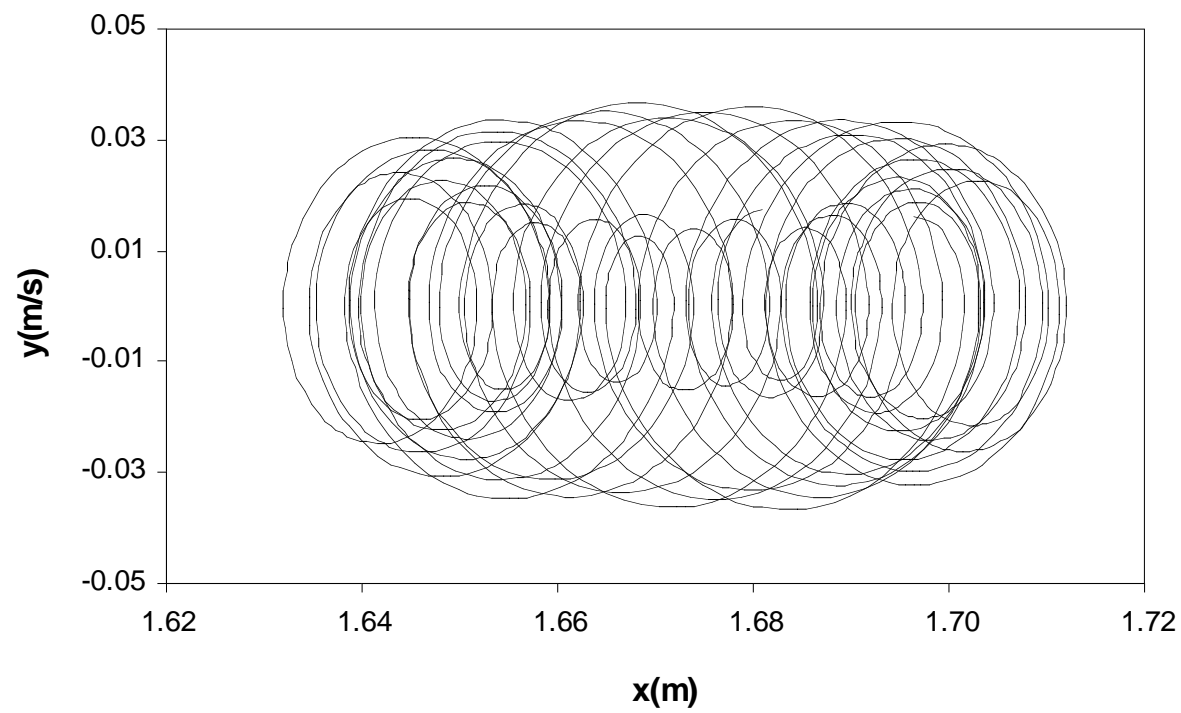

Fig. (7). Phase plot of the response (x) due to total second order wave force $[5 \mathrm{~m} / 5 \mathrm{~s}$ wave; $(x, y)=(0,0)]$.

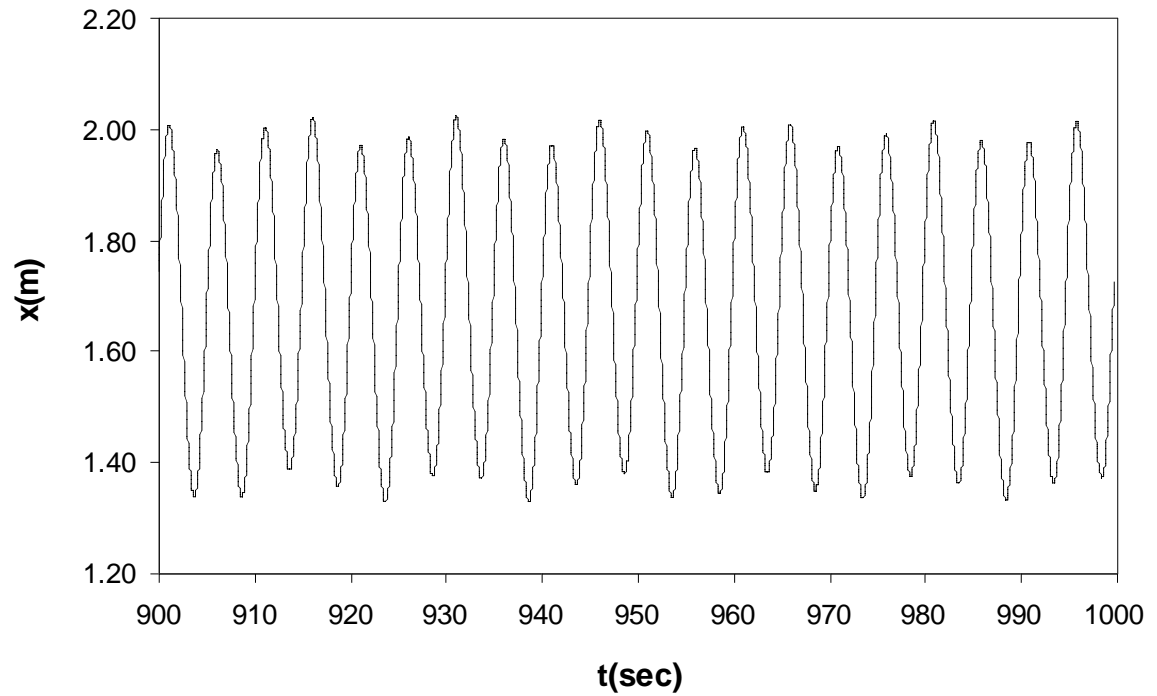

Fig. (8). Time history of the response $(x)$ due to the combination of primary and second order wave force $[5 \mathrm{~m} / 5 \mathrm{~s} w a v e ;(x, y)=(0,0)]$. 


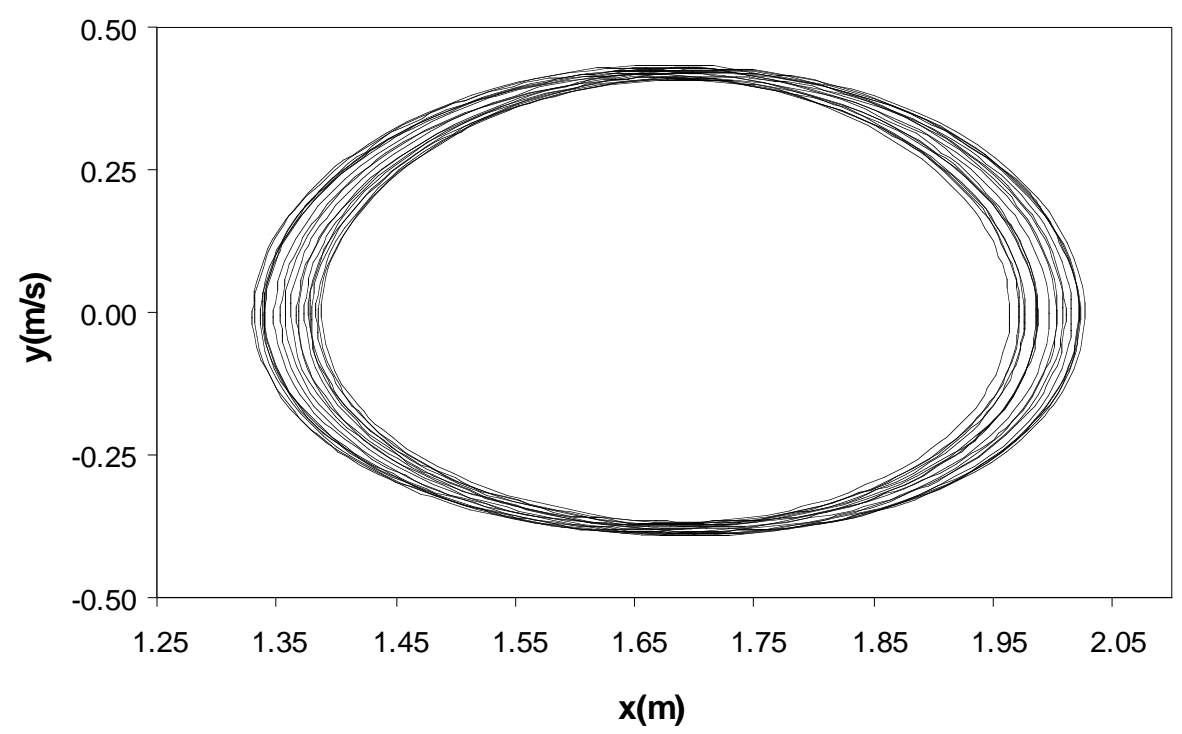

Fig. (9). Phase plot of the response $(\mathrm{x})$ due to the combination of primary and second order wave force $[5 \mathrm{~m} / 5 \mathrm{~s} w a v e ;(\mathrm{x}, \mathrm{y})=(0,0)]$.

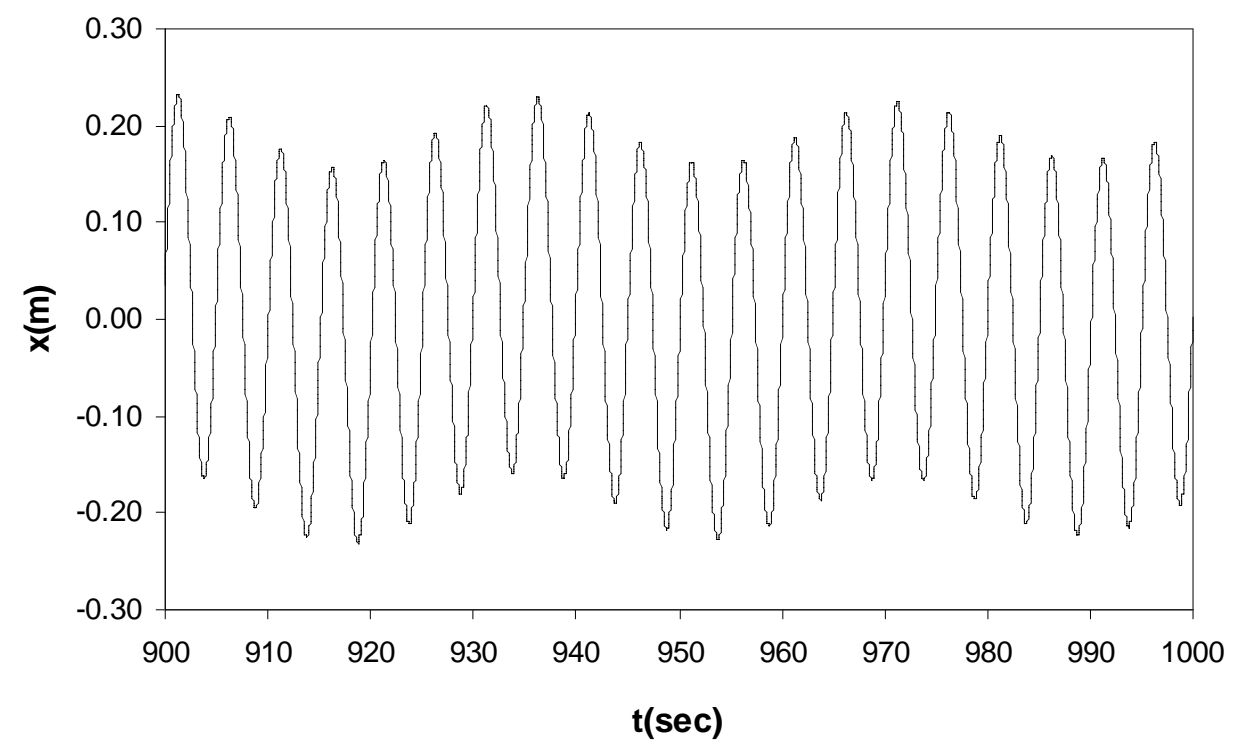

Fig. (10). Time history of the response (x) due to wind force.

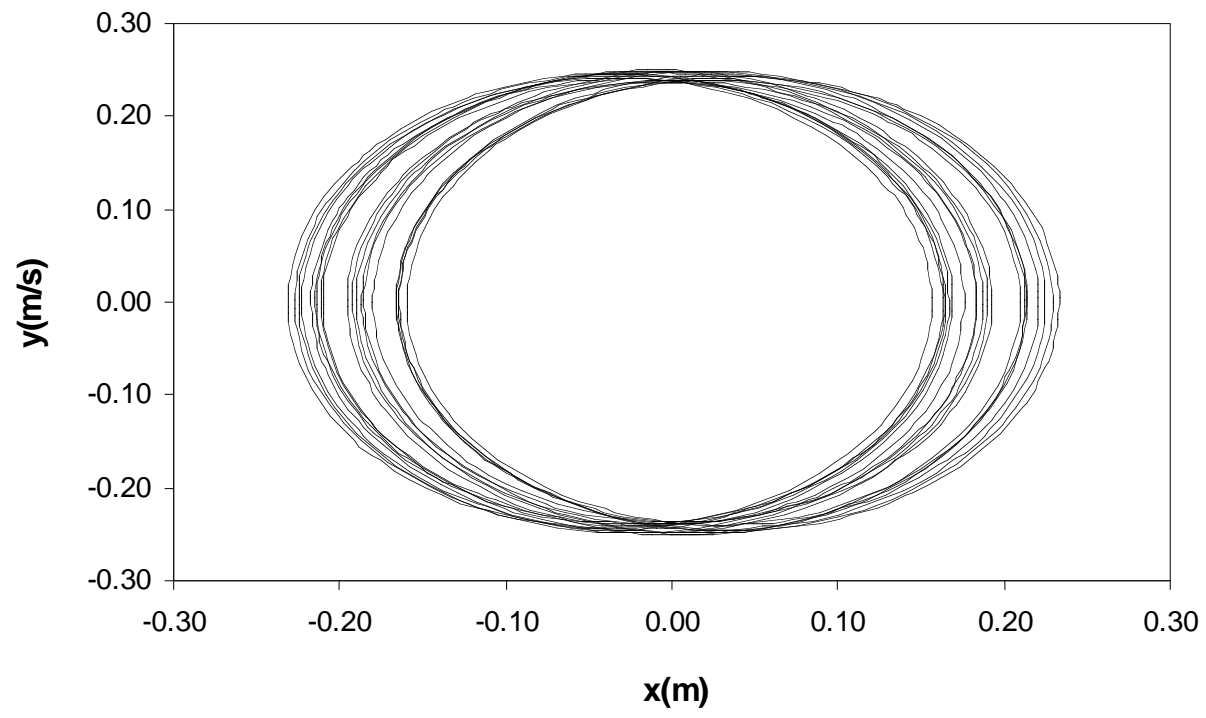

Fig. (11). Phase plot of the response (x) due to wind force. 


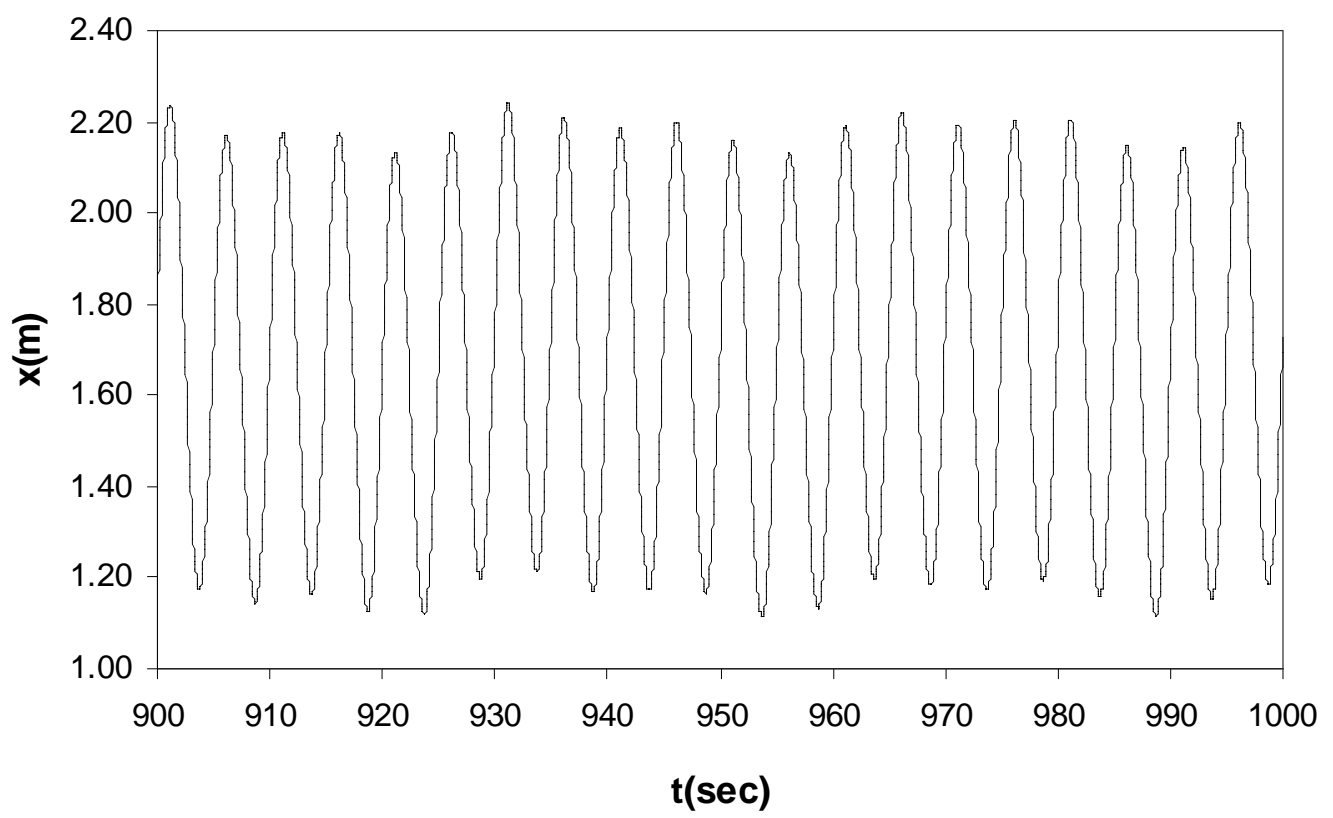

Fig. (12). Time history of the response (x) due to the combination of total wave force $[5 \mathrm{~m} / 5 \mathrm{~s}$ wave] and wind force.

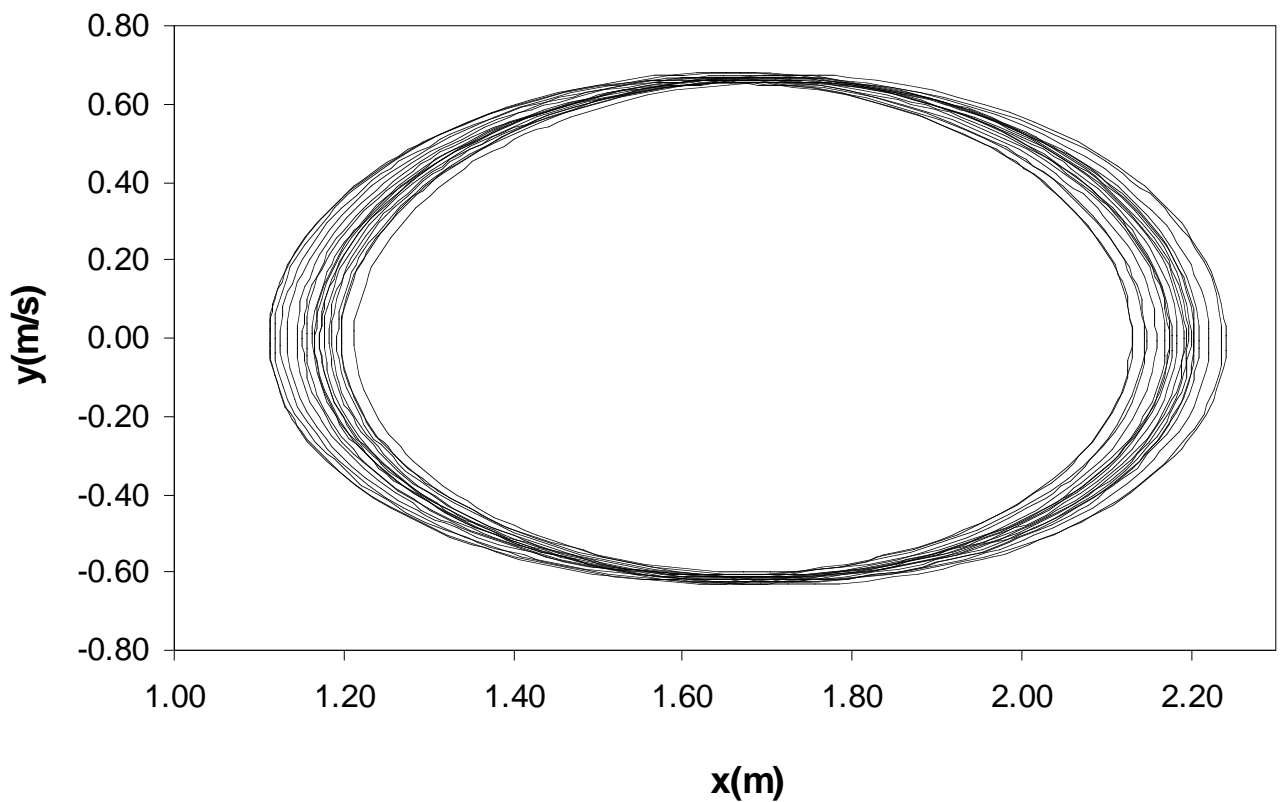

Fig. (13). Phase plot of the response $(x)$ due to the combination of total wave force $[5 \mathrm{~m} / 5 \mathrm{~s}$ wave] and wind force.

For a $5 \mathrm{~m} / 5 \mathrm{sec}$ wave, the response of the moored buoy does not show any stability problem for (i) the primary wave force (ii) the second order wave force and (iii) combination of the primary and second order wave force (iv) wind force and (v) combination of wave and wind forces.

\section{Responses Due to $12 \mathrm{~m} / 10$ sec Wave}

Fig. (14) shows the response of the buoy for a 12 $\mathrm{m} / 10 \mathrm{sec}$ wave for primary wave force with initial conditions $(\mathrm{x}, \mathrm{y}=0,0)$. The maximum amplitude of the response is about $5.25 \mathrm{~m}$. The nature of response is periodic with a period of 10 seconds. The phase plot of the response (Fig. 15) shows symmetry breaking bifurcation. This shows that there is a possibility of dynamic instability in the form of bifurcation of response although the response may be within the limits.

The response of the buoy due to total second order force is shown in (Fig. 16) for the initial condition $(x, y=0,0)$. The response is periodic with maximum response equal to 1.74 $\mathrm{m}$. The significant increase in the maximum response is due to the presence of steady component $F_{m}{ }^{(2)}$ of the second order force. The phase plot (Fig. 17) shows that the system is stable under the second order force for 10-second wave. This is expected since the second order force is a double frequency force having a period of 5 second for which the response was found to be stable. 


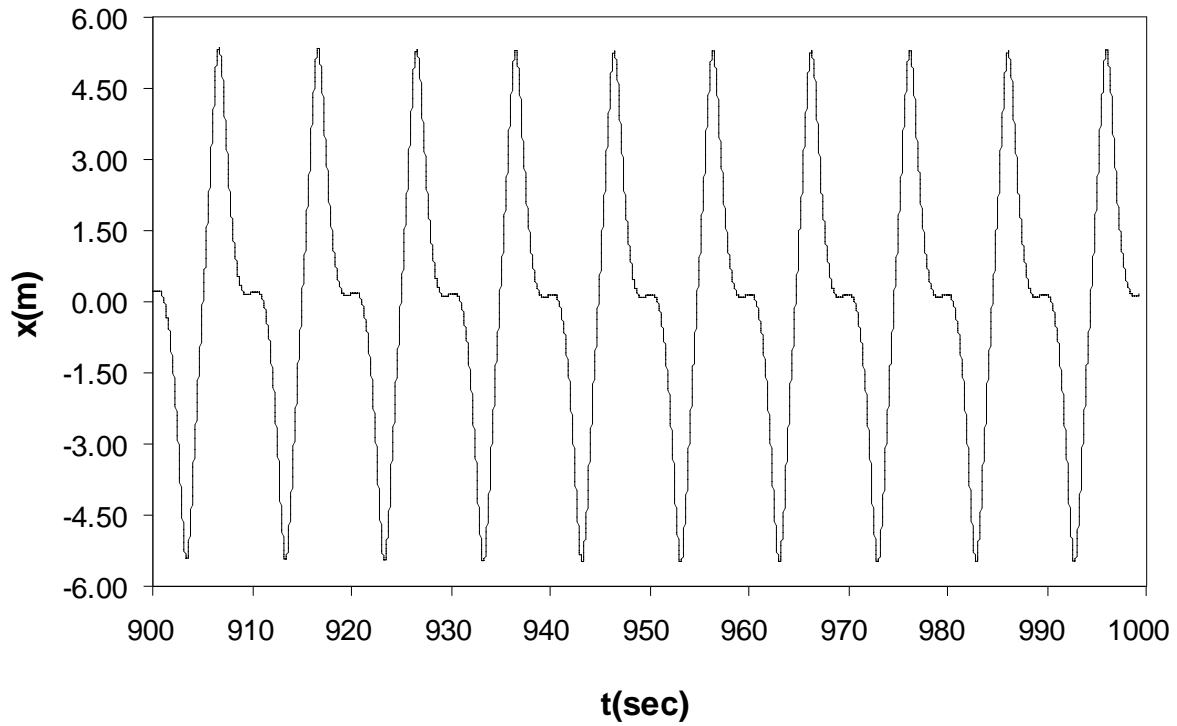

Fig. (14). Time history of the response $(x)$ due to the primary wave force $[12 \mathrm{~m} / 10 \sec$ wave; $(x, y)=(0,0)]$.

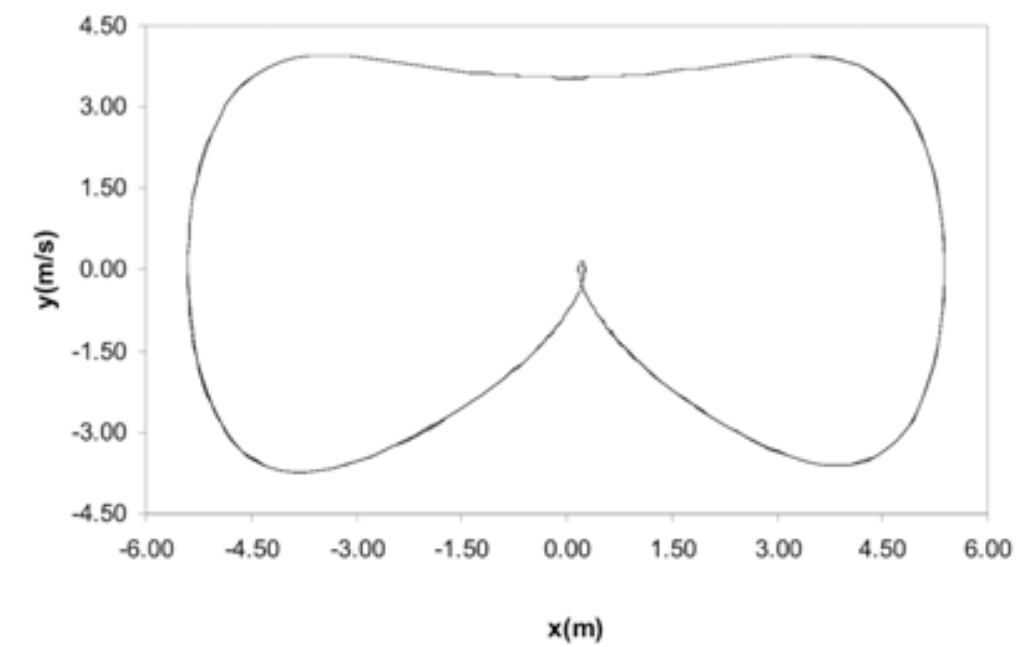

Fig. (15). Phase plot of the response (x) due to the primary wave force $[12 \mathrm{~m} / 10$ s wave; $(x, y)=(0,0)]$.

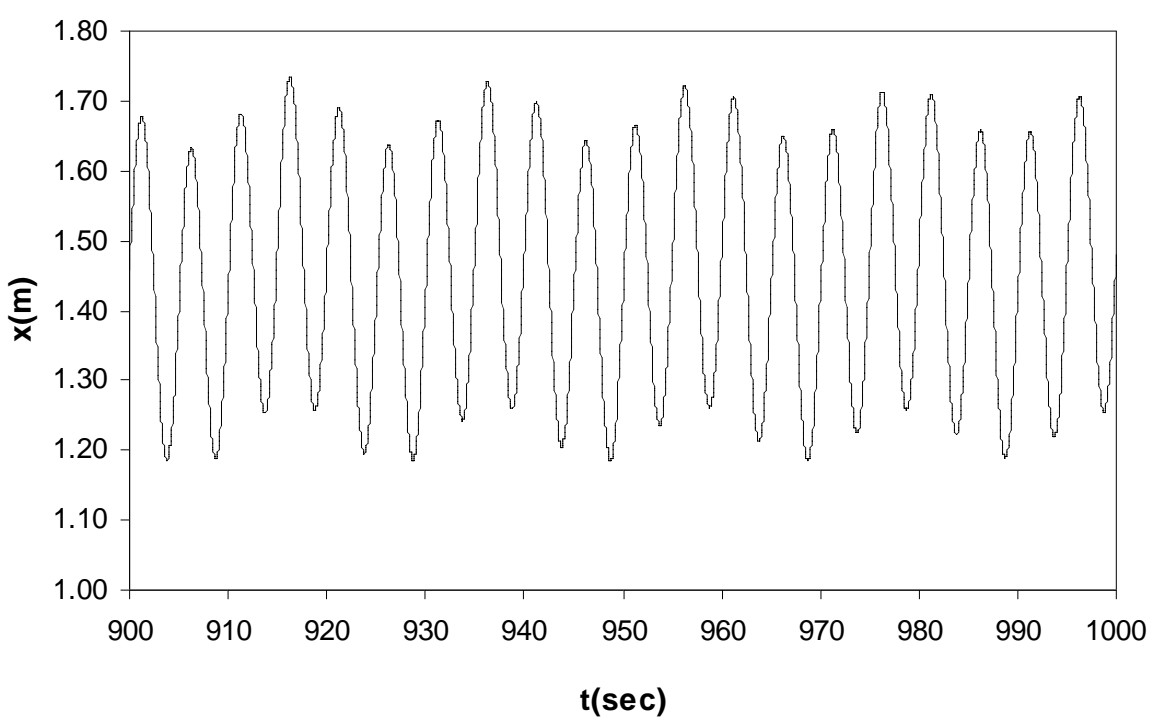

Fig. (16). Time history of the response $(x)$ due to total second order wave force $[12 \mathrm{~m} / 10 \sec$ wave; $(x, y)=(0,0)]$. 


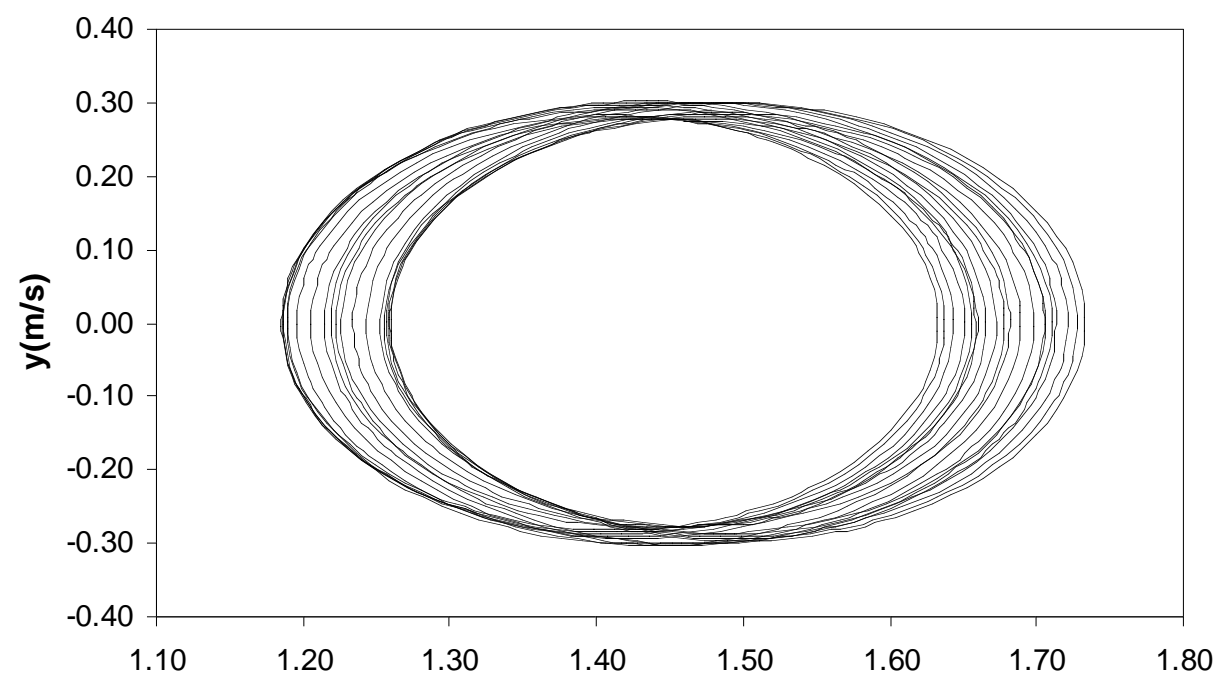

$x(m)$

Fig. (17). Phase plot of the response $(x)$ due to total second order wave force $[12 \mathrm{~m} / 10$ s wave; $(x, y)=(0,0)]$.

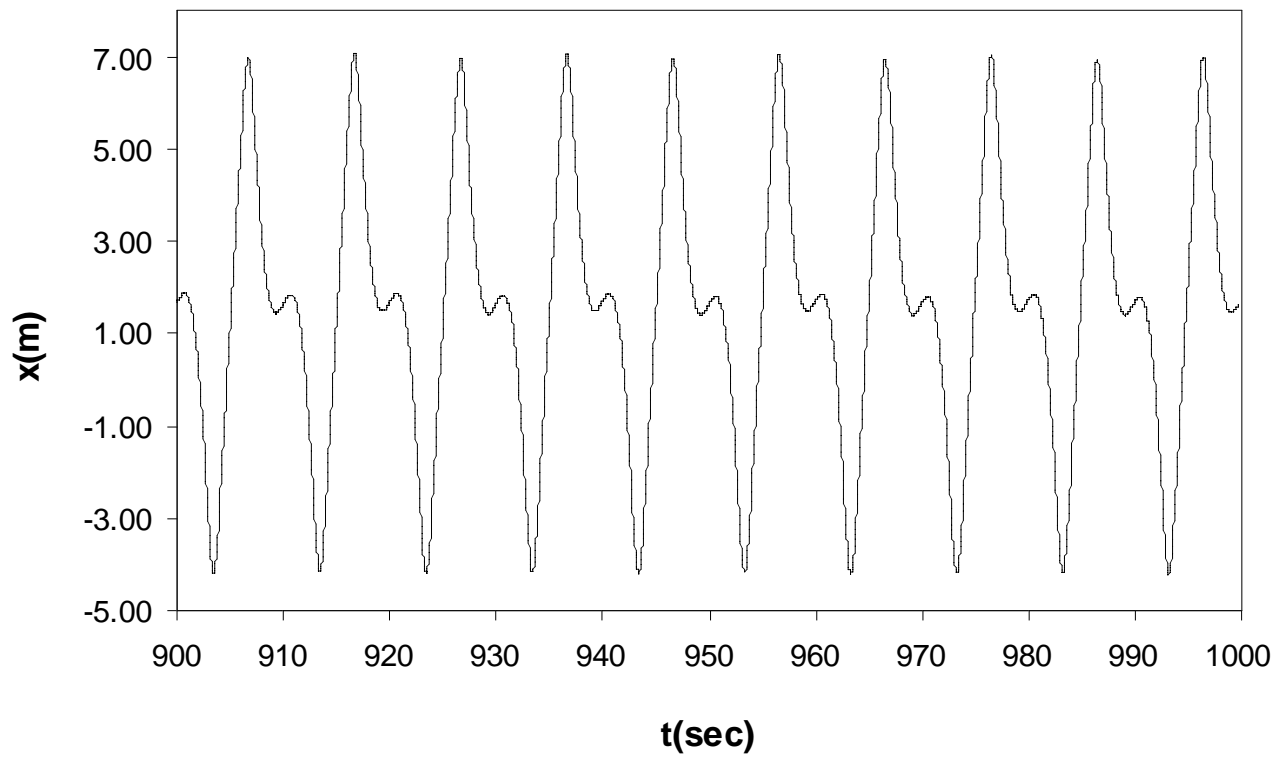

Fig. (18). Time history of the response $(x)$ due to the combination of primary and second order wave force $[12 \mathrm{~m} / 10 \mathrm{~s} w a v e ;(x, y)=(0,0)]$.

The response and phase plots of the buoy when subjected to total wave force, i.e. the combination of first and second order wave forces, are shown in Figs. (18 and 19) respectively, for the initial condition $(x, y=0,0)$. It is seen that the response is periodic. The maximum response is about $6.99 \mathrm{~m}$. The phase plot (Fig. 19) shows symmetry breaking bifurcation. This was expected as primary wave force governs the response. Moreover, the wave frequency lies in the frequency bounds for which it was predicted that instability may occur Thus, there is a problem of instability due to $(12 \mathrm{~m} / 10 \mathrm{sec})$ total wave force.

\section{Response Under Wind Force}

The response and phase plots of the buoy when subjected to the wind force of frequency $0.6283 \mathrm{rad} / \mathrm{sec}$ are shown in
Figs. (20) and (21) respectively for the initial condition $(x, y$ $=0,0)$. From the Figs. (20) and (21), it is seen that the response is periodic and the phase plot is symmetrical. The maximum response is about $3 \mathrm{~m}$.

\section{Response Under the Combination of Wave and Wind Force}

The response due to combination of total wave force $(12 \mathrm{~m} / 10 \mathrm{sec}$ wave) and wind force is as shown in the Fig. (22). The response is periodic with maximum amplitude equal to about $10 \mathrm{~m}$. The phase plot of the response (Fig. 23) shows symmetry breaking bifurcation under the combination of both wave and wind force.

Thus, for the $12 \mathrm{~m} / 10 \mathrm{sec}$ wave, moored system exhibits problems of instability when it is subjected to either primary 


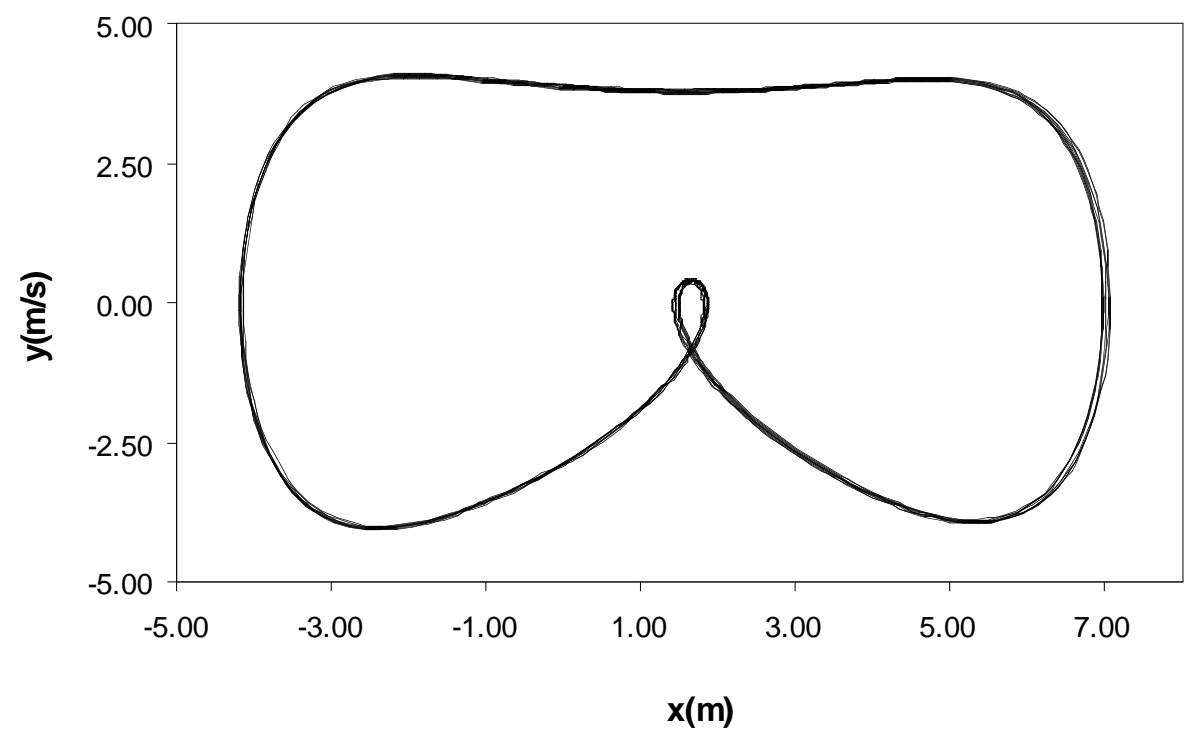

Fig. (19). Phase plot of the response $(x)$ due to the combination of primary and second order wave force $[12 \mathrm{~m} / 10 \mathrm{~s}$ wave; $(\mathrm{x}, \mathrm{y})=(0,0)]$.

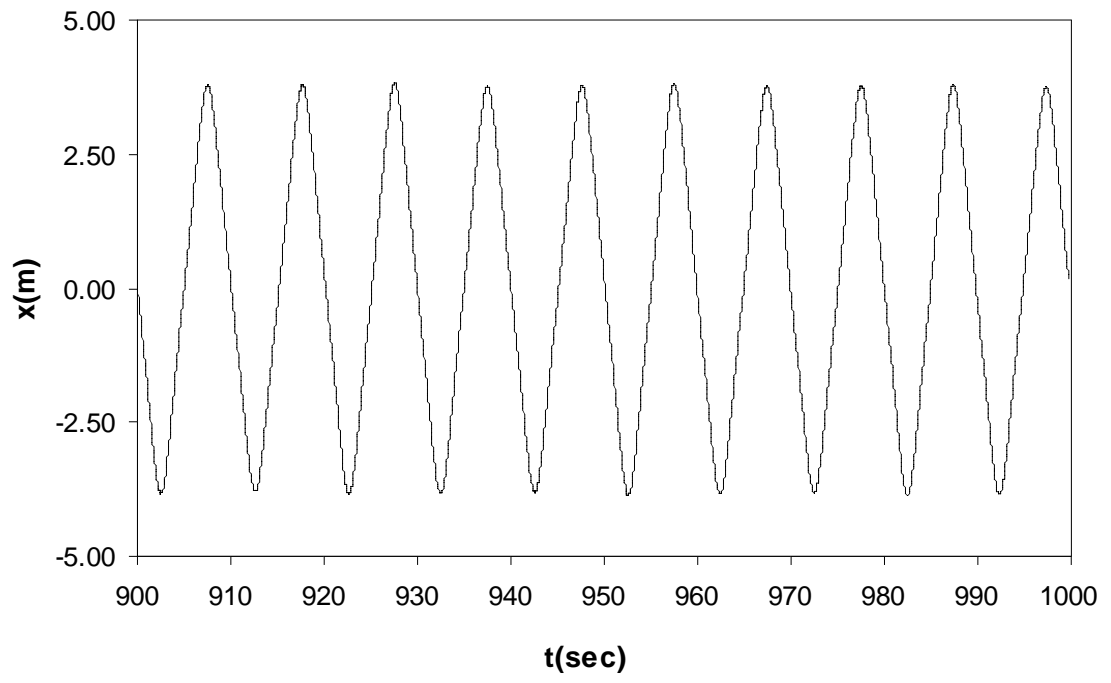

Fig. (20). Time history of the response (x) due to wind force.

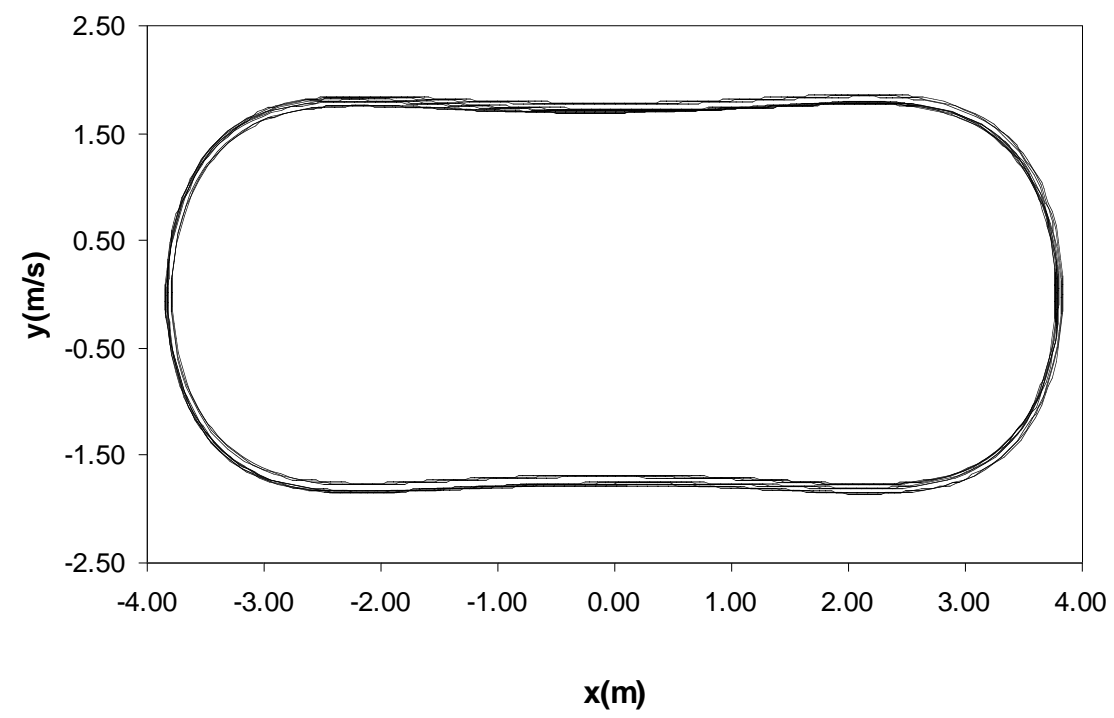

Fig. (21). Phase plot of the response (x) due to wind force. 


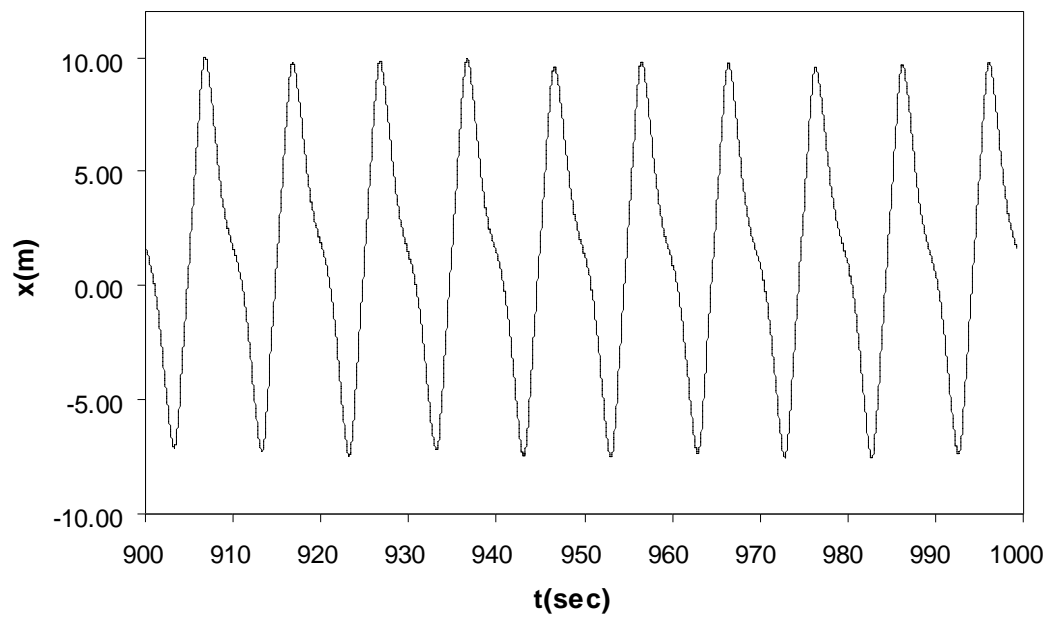

Fig. (22). Time history of the response (x) due to the combination of total wave force $[12 \mathrm{~m} / 10 \mathrm{sec}$ wave] and wind force.

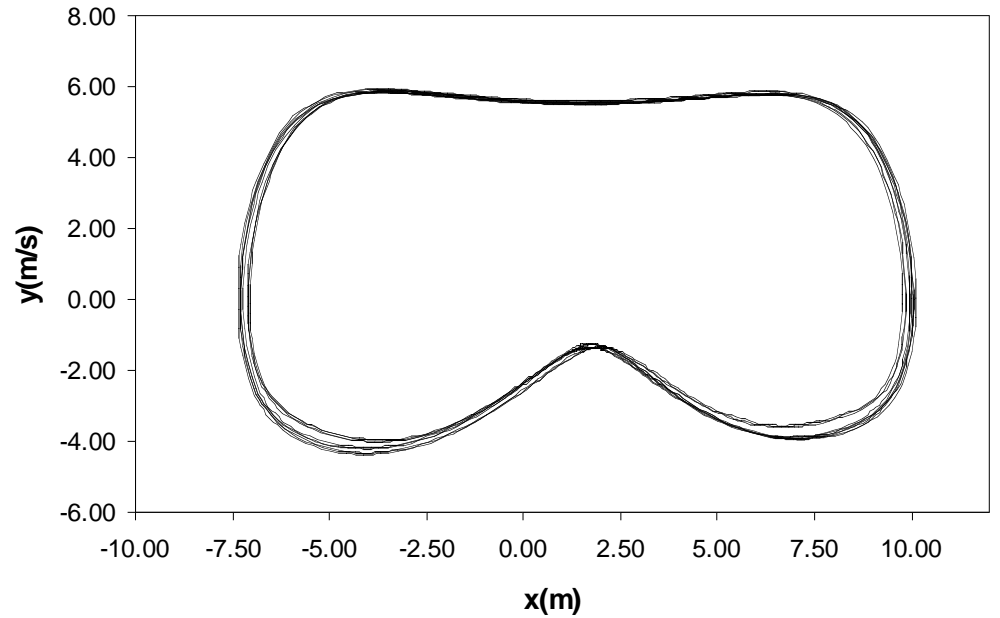

Fig. (23). Phase plot of the response (x) due to the combination of total wave force $[12 \mathrm{~m} / 10 \mathrm{sec}$ wave] and wind force.

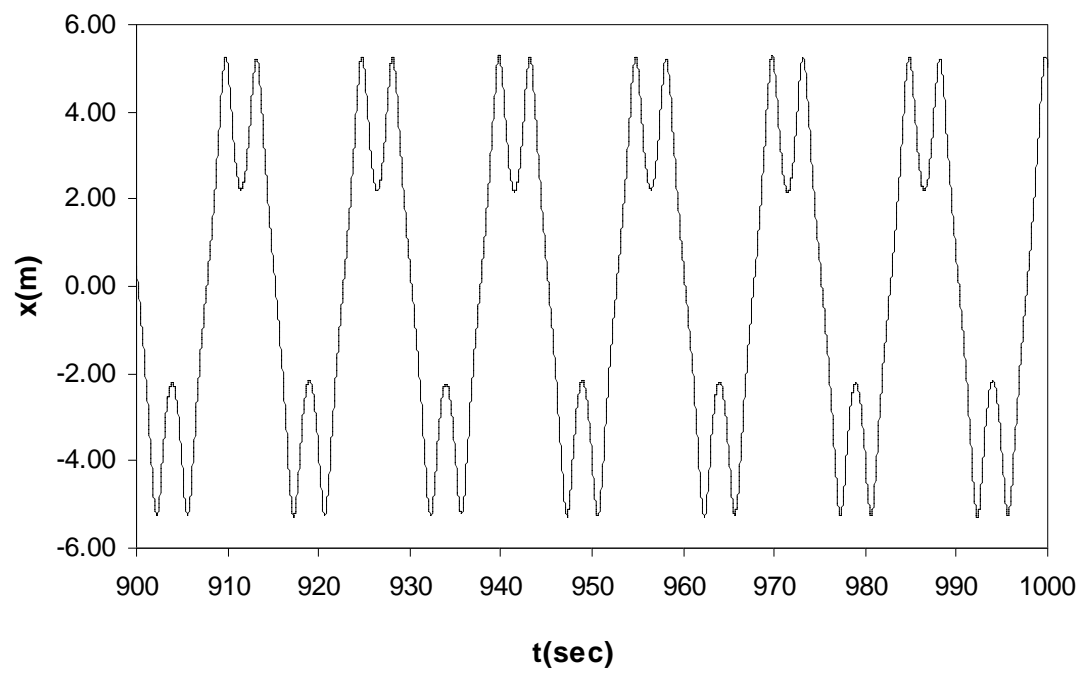

Fig. (24). Time history of the response (x) due to the primary wave force $[18 \mathrm{~m} / 15 \mathrm{sec}$ wave; $(\mathrm{x}, \mathrm{y})=(0,0)]$.

or the combination of primary and second order wave force or the combination total wave forces and wind.

\section{Responses Due to $18 \mathrm{~m} / 15 \mathrm{sec}$ Wave}

From the characteristics of the approximate responses discussed earlier, it may be expected that the system would exhibit problems of instability for $18 \mathrm{~m} / 15 \mathrm{sec}$ wave. In order to verify it, the response and phase plots are obtained.

Figs. (24) and (25) show the response and phase plots respectively of the moored system due to $18 \mathrm{~m} / 15 \mathrm{sec}$ primary wave for the initial condition $(x, y=0,0)$. Figures show the 


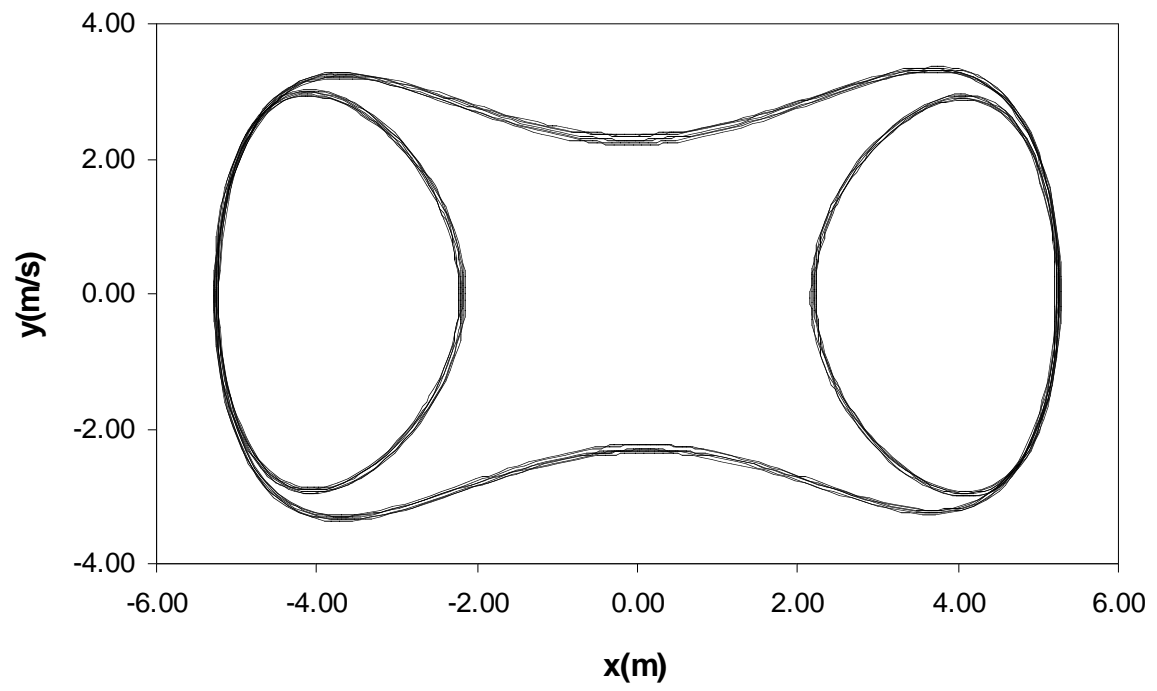

Fig. (25). Phase plot of the response $(x)$ due to the primary wave force $[18 \mathrm{~m} / 15 \mathrm{sec}$ wave; $(x, y)=(0,0)]$.

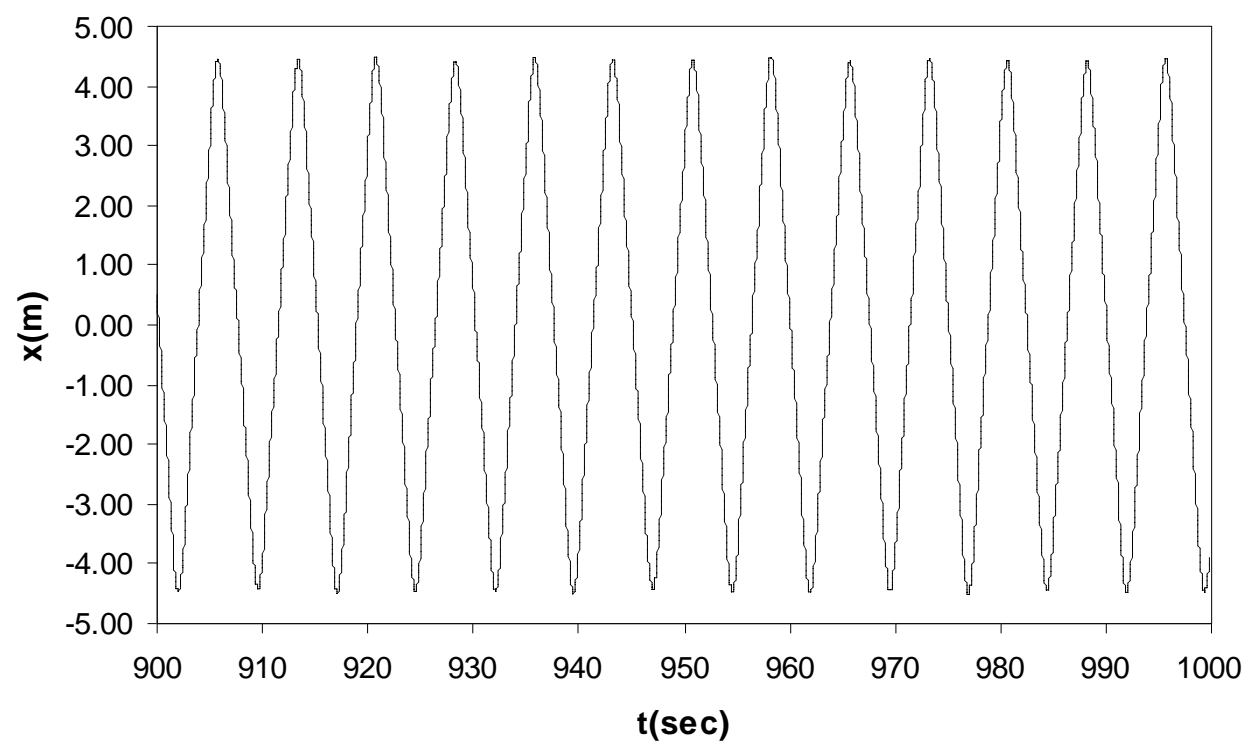

Fig. (26). Time history of the response $(\mathrm{x})$ due to total second order wave force $[18 \mathrm{~m} / 15 \mathrm{sec}$ wave; $(\mathrm{x}, \mathrm{y})=(0,0)]$.

response to be sub-harmonic (T-periodic solution). The maximum response obtained is $5.30 \mathrm{~m}$. As expected, for the $18 \mathrm{~m} / 15 \mathrm{sec}$ wave, moored system exhibits problems of instability.

Figs. (26) and (27) show the response and phase plots of the moored system due to second order wave force. The response is harmonic and the phase plot is symmetrical. For the changed initial condition $(x, y=-1,0.5)$, identical response and phase plots are obtained. These plots are identical to those shown for the initial condition $(x, y=0,0)$.

Thus, the moored system does not show any instability problem under second order wave force for $18 \mathrm{~m} / 15 \mathrm{sec}$ wave.

Response and phase plots for the wave forces comprising of both primary and second order forces have been plotted in Figs. (28) and (29) for the initial condition $(x, y=0,0)$. The maximum response is $9.40 \mathrm{~m}$. The response, shown in Fig. (28), is periodic with a time period of 15 seconds. The phase plot (Fig. 29) represents symmetry breaking phenomenon. It is interesting to observe that the effect of second order wave force was to change the nature of phase plot from that observed for primary wave force alone. While the phase plot for primary wave force showed $n T$ periodic solution, the phase plot for the combined action of wave force showed symmetry breaking. Thus, in this particular example, the second order effect contributed to change of instability phenomena (i.e. from $n T$ periodic solution under primary wave force to symmetry breaking solution under the action of combined wave force).

\section{Response Under Wind Force}

Figs. (30) and (31) show response of moored buoy under the action of wind force of frequency $0.4188 \mathrm{rad} / \mathrm{s}$. The figures show a period doubling phenomenon. The response is periodic with a time period of 30 seconds. The maximum amplitude is $3.8 \mathrm{~m}$. 


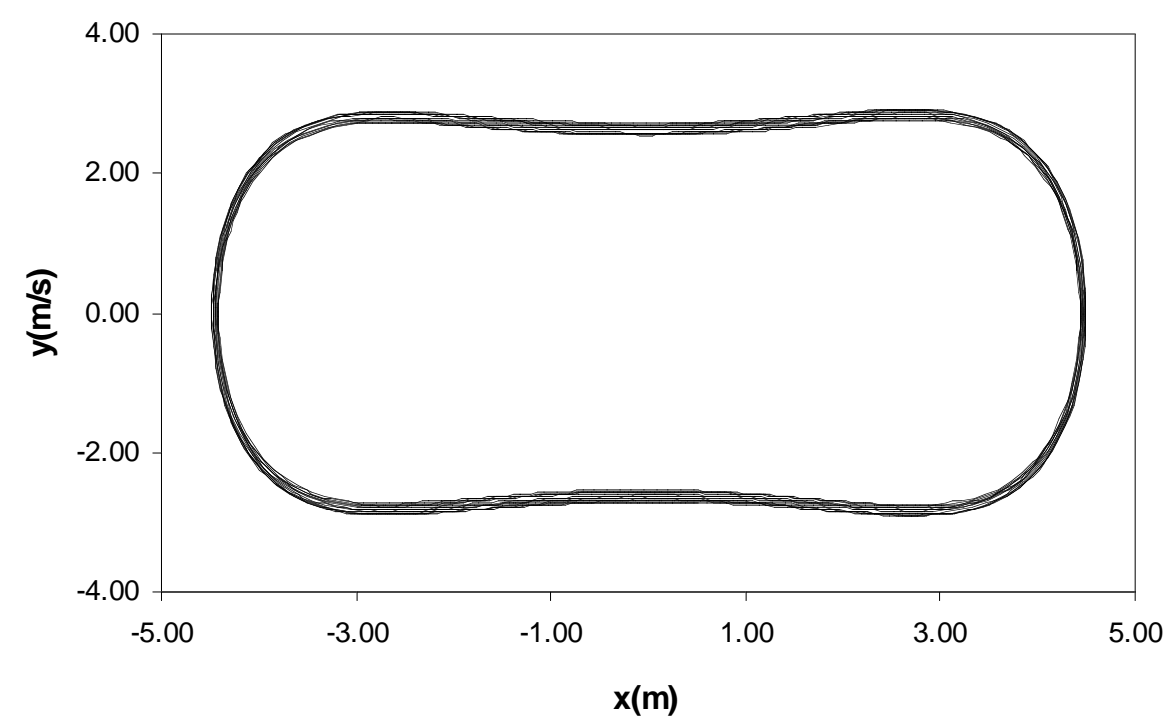

Fig. (27). Phase plot of the response $(\mathrm{x})$ due to total second order wave force $[18 \mathrm{~m} / 15 \mathrm{sec}$ wave; $(\mathrm{x}, \mathrm{y})=(0,0)]$.

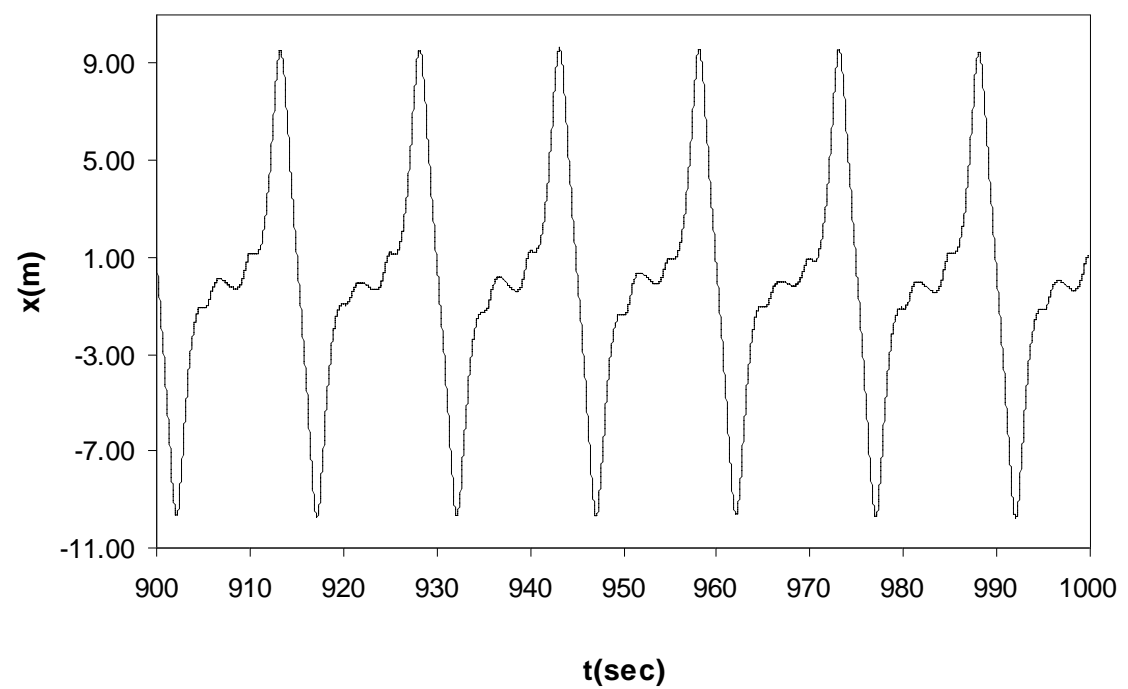

Fig. (28). Time history of the response $(x)$ due to the combination of primary and second order wave force $[18 \mathrm{~m} / 15 \mathrm{sec} w a v e ;(x, y)=(0,0)]$.

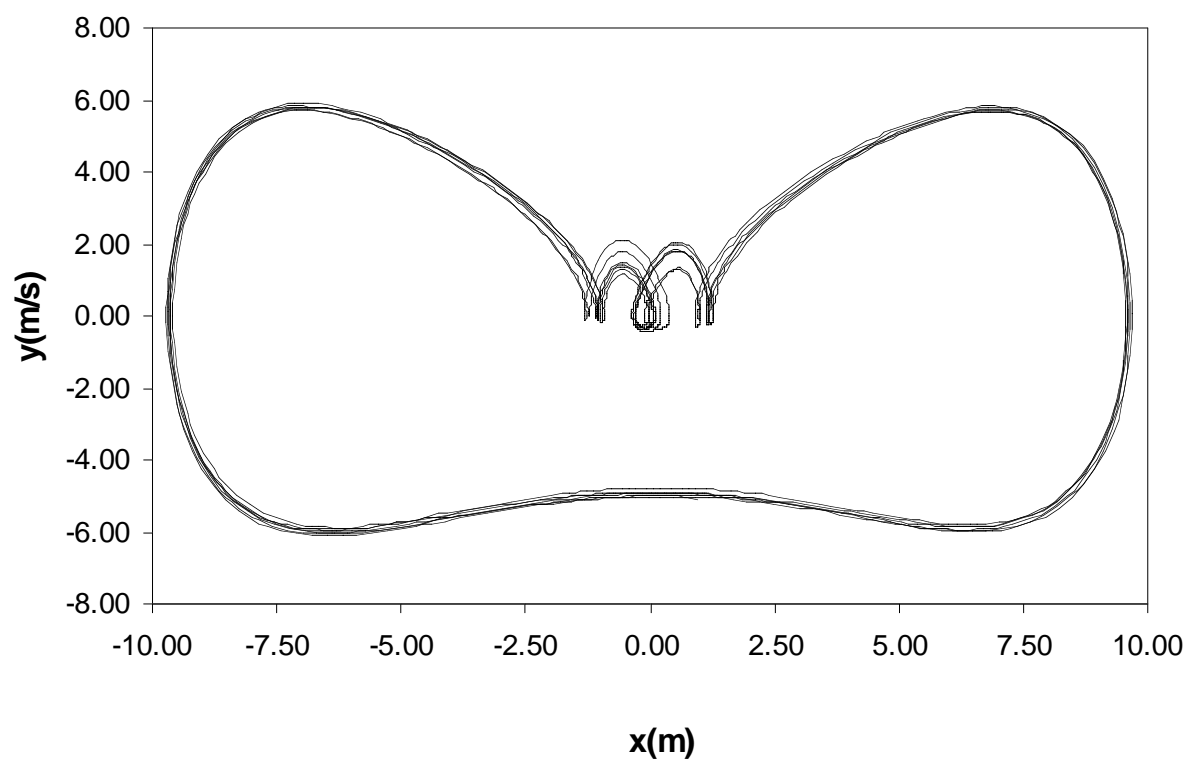

Fig. (29). Phase plot of the response (x) due to the combination of primary and second order wave force $[18 \mathrm{~m} / 15 \mathrm{sec} w a v e ;(x, y)=(0,0)]$. 


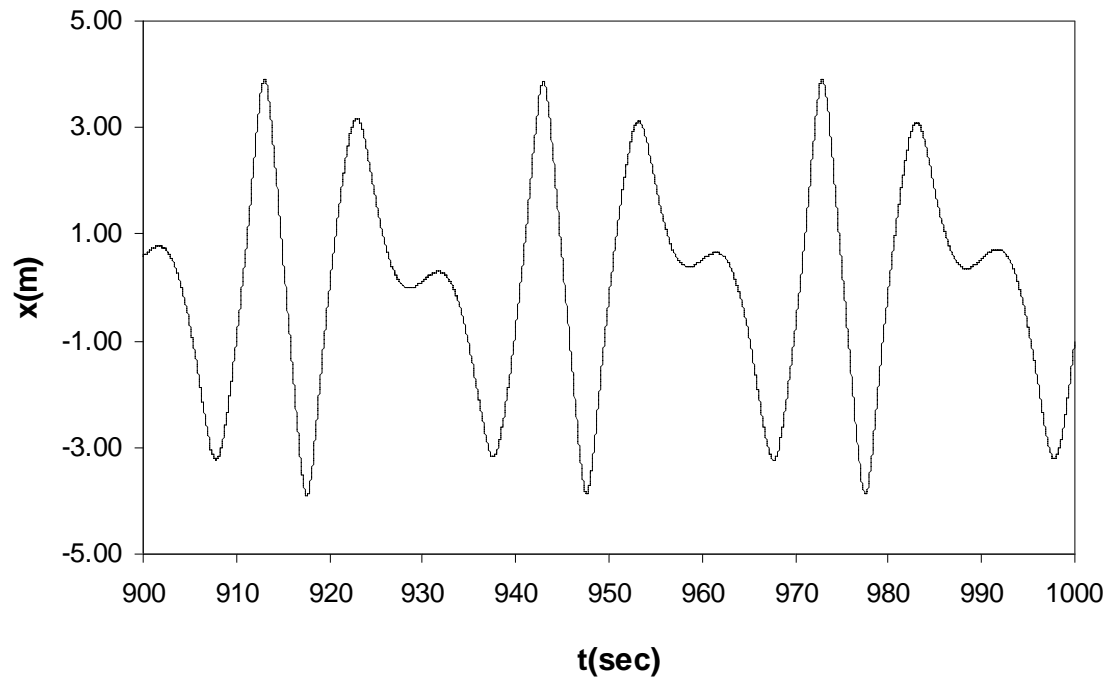

Fig. (30). Time history of the response (x) due to wind force.

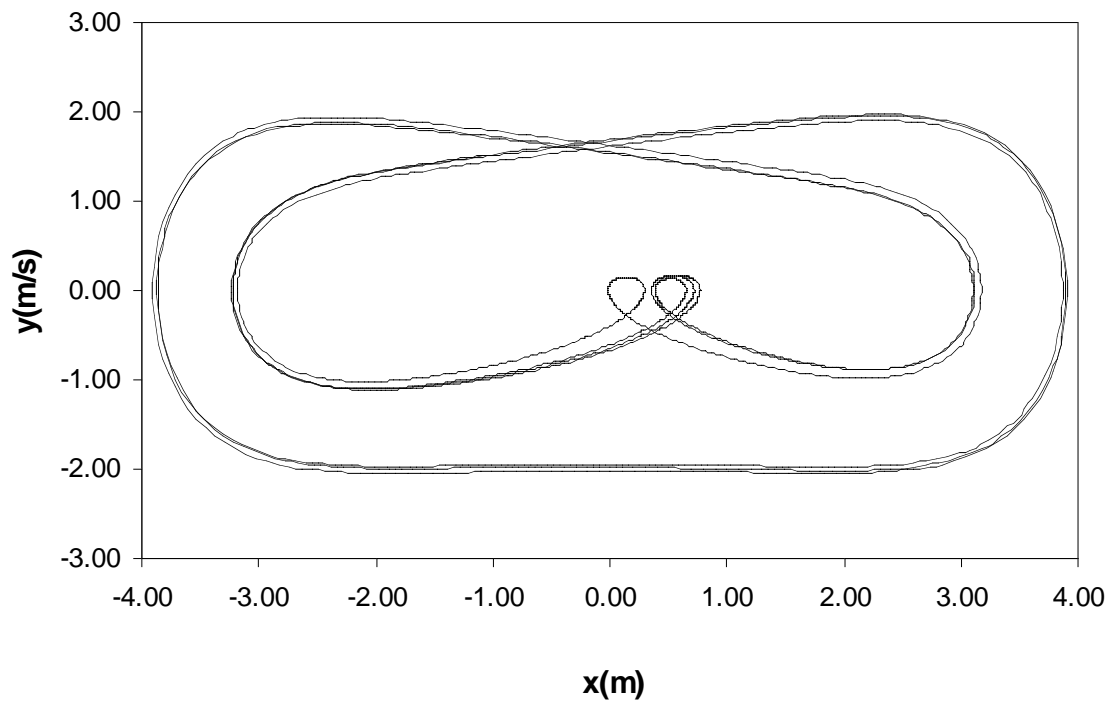

Fig. (31). Phase plot of the response (x) due to wind force.

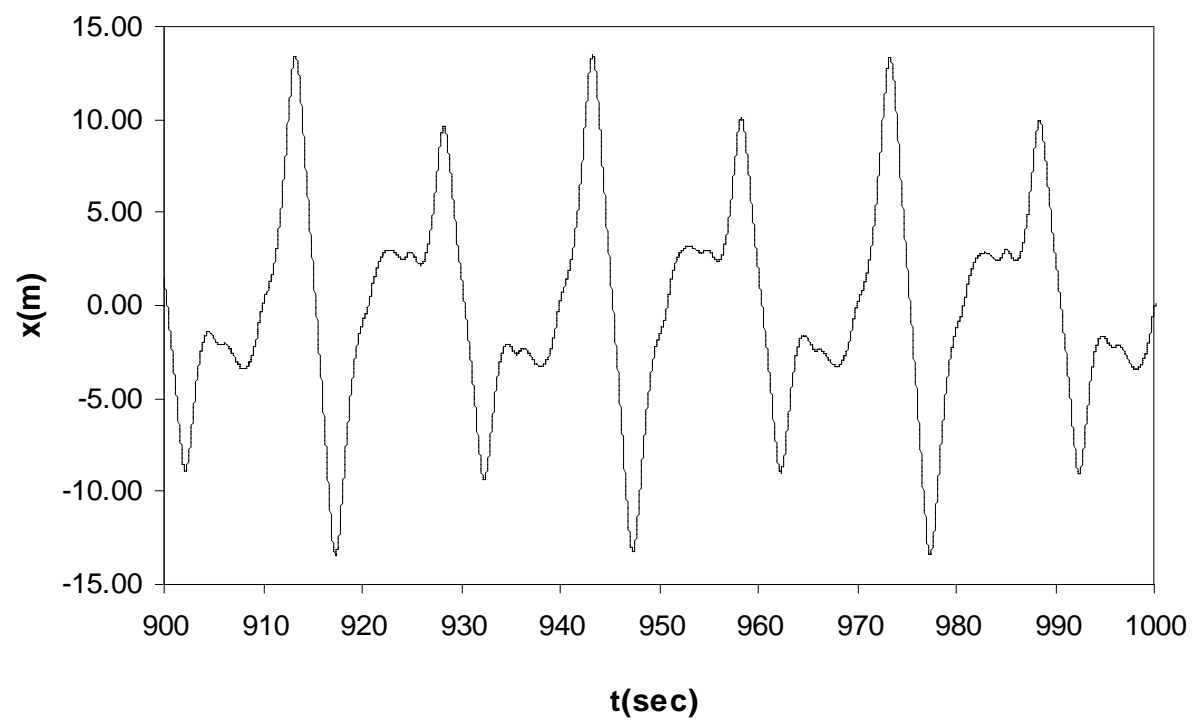

Fig. (32). Time history of the response $(x)$ due to the combination of total wave force $[18 \mathrm{~m} / 15 \mathrm{sec}$ wave] and wind force. 


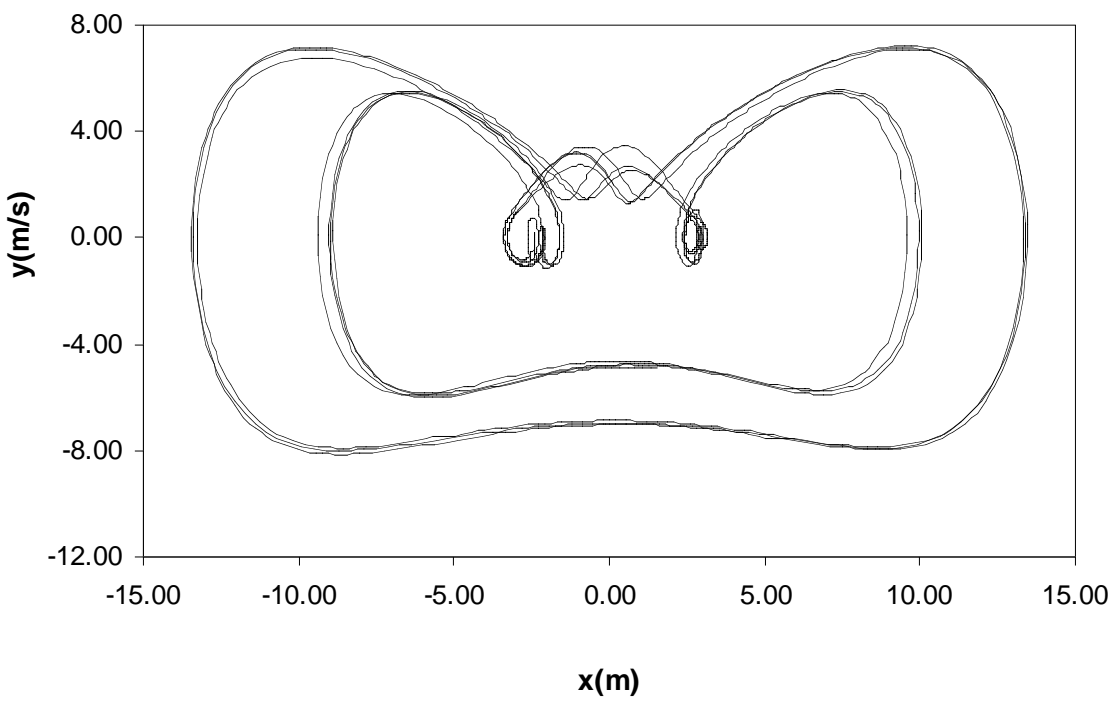

Fig. (33). Phase plot of response (x) due to the combination of total wave force $[18 \mathrm{~m} / 15 \mathrm{~s}$ wave] and wind force.

\section{Response Under the Combination of Wave and Wind} Force

Figs. (32) and (33) show response of moored buoy under the action of combination of $18 \mathrm{~m} / 15 \mathrm{sec}$ wave force and wind force of frequency $0.4188 \mathrm{rad} / \mathrm{s}$. The figures show a period doubling phenomenon. The response is periodic with a time period of 30 seconds. The maximum amplitude of the response is $13.2 \mathrm{~m}$. Thus the moored system, as expected, show instability under the action of combination total wave and wind force.

Thus, for $18 \mathrm{~m} / 15 \mathrm{sec}$ wave, the moored system exhibits instability problem when it is subjected to either primary or the combination of primary and second order wave forces or wind force or the combination of total wave force and wind force.

\section{CONCLUSIONS}

The stability of a moored buoy is investigated under regular sea-state and wind forces. Excitations due to primary (first order) wave force, second order wave force and a combination of the two, wind force and the combination of wave and wind forces are considered in the stability analysis. Both primary and second order wave forces are calculated using the procedure adopted by [12] which duly considers the effects of diffraction, added mass and hydrodynamic damping. Nonlinearity in the system causing the problem of instability, is offered by the nonlinear restoring force of the mooring lines. The nonlinear force-excursion relationship of the mooring system is represented by a 5th order antisymmetrical polynomial. Using the two term harmonic balance method [2], the approximate response of the system to harmonic excitations is obtained. The frequency ranges in which instability phenomena can occur are derived using Eqs. 46 and 47. Within this frequency range, various instability phenomena are shown to occur for the moored system. The stability analyses of the moored system are then carried out for three regular waves namely $5 \mathrm{~m} / 5 \mathrm{sec}$, $12 \mathrm{~m} / 10 \mathrm{sec}$ and $18 \mathrm{~m} / 15 \mathrm{sec}$ and wind forces of the same frequency. The results of the stability analysis lead to the following conclusions.

1. For $5 \mathrm{~m} / 5 \mathrm{sec}$ regular wave and wind force of frequency $1.2566 \mathrm{rad} / \mathrm{sec}$, the moored system is found to be stable under the action of first order, second order and the combination of first and second order wave forces (total wave forces), wind force and the combination of wave and wind forces.

2. For a $12 \mathrm{~m} / 10 \mathrm{sec}$ regular wave, the system shows symmetry breaking bifurcation due to first order wave force but it is stable under second order wave forces and wind force. The system shows instability problem due to the combination of primary wave force and total second order wave forces. This may be due to the fact that primary wave force governs the motion. Instability occurs under the combination of wave and wind force.

3. For an $18 \mathrm{~m} / 15 \mathrm{sec}$ regular wave, the system shows sub harmonic response due to primary wave force, whereas the system is stable under total second order wave force. The system shows symmetry breaking bifurcation due to total wave force, wind force and combination of wave and wind force.

4. For $12 \mathrm{~m} / 10 \mathrm{sec}$ and $18 \mathrm{~m} / 15 \mathrm{sec}$ regular waves, the system is found to be stable when subjected to second order wave force.

5. Thus, the instability phenomena (period doubling or symmetry breaking bifurcation etc.) observed under the combined action of primary and second order wave forces for $12 \mathrm{~m} / 10 \mathrm{sec}$ and $18 \mathrm{~m} / 15 \mathrm{sec}$ regular waves are not due to the natural consequences of second order effects. However, for $18 \mathrm{~m} / 15 \mathrm{sec}$ regular wave, the second order effect contributed to change of instability phenomena (i.e. from $n T$ periodic solution under primary wave force to symmetry breaking solution under the action of combined wave force). 
6. Wind forces with lower frequencies can create problems with the stability of the structure, as is seen with the case when wind force frequency is reduced from $1.2566 \mathrm{rad} / \mathrm{sec}$ to $0.4183 \mathrm{rad} / \mathrm{sec}$.

\section{APPENDIX I}

$\mathrm{E}_{1}+\mathrm{E}_{2}+\mathrm{E}_{3}+\mathrm{E}_{4}+\mathrm{E}_{5}+\mathrm{E}_{6}+\mathrm{E}_{7}+\mathrm{E}_{8}+\mathrm{E}_{9}=0$

where $\mathrm{E}_{1}=-\omega^{2} A_{1} \cos \phi+f_{1} \sin \phi-\delta \omega A_{1} \sin \phi+c_{1} A_{1} \cos \phi$

$\mathrm{E}_{2}=\frac{3}{4} c_{3} A_{1}^{3} \cos \phi$

$\mathrm{E}_{3}=\frac{3}{4} c_{3} A_{1}^{2} A_{3}(\cos \alpha \cos 2 \phi+\sin \alpha \sin 2 \phi)$

$\mathrm{E}_{4}=\frac{3}{2} c_{3} A_{1} A_{3}^{2} \cos \phi$

$\mathrm{E}_{5}=\frac{5}{8} c_{5} A_{1}^{4}\left\{A_{1} \cos \phi+2 A_{3} \cos \phi \cos (\alpha-2 \phi)\right\}$

$\mathrm{E}_{6}=\frac{15}{4} c_{5} A_{1}^{3} A_{3}^{2} \cos \phi$

$\mathrm{E}_{7}=\frac{5}{16} c_{5} A_{1}^{4} A_{3} \cos (4 \phi-\alpha)$

$\mathrm{E}_{8}=\frac{15}{8} c_{5} A_{1}^{2} A_{3}^{3}(\cos \alpha \cos 2 \phi-\sin \alpha \sin 2 \phi)$

$\mathrm{E}_{9}=\frac{15}{8} c_{5} A_{1} A_{3}^{4} \cos \phi$

(ii) Equating $\sin \omega t$ terms equal to zero,

$\mathrm{E}_{11}+\mathrm{E}_{12}+\mathrm{E}_{13}+\mathrm{E}_{14}+\mathrm{E}_{15}+\mathrm{E}_{16}+\mathrm{E}_{17}+\mathrm{E}_{18}+\mathrm{E}_{19}=0$

where $\mathrm{E}_{11}=\omega^{2} A_{1} \sin \phi+f_{1} \cos \phi-\delta \omega A_{1} \cos \phi-c_{1} A_{1} \sin \phi$

$\mathrm{E}_{12}=-\frac{3}{4} c_{3} A_{1}^{3} \sin \phi$

$\mathrm{E}_{13}=-\frac{3}{4} c_{3} A_{1}^{2} A_{3}(\sin \alpha \cos 2 \phi-\cos \alpha \sin 2 \phi)$

$\mathrm{E}_{14}=-\frac{3}{2} c_{3} A_{3}^{2} A_{1} \sin \phi$

$\mathrm{E}_{15}=-\frac{5}{8} c_{5} A_{1}^{4}\left\{A_{1} \sin \phi+2 A_{3} \sin (\alpha-2 \phi)\right\}$

$\mathrm{E}_{16}=-\frac{30}{8} c_{5} A_{1}^{3} A_{3}^{2} \sin \phi$
7. The responses due to wind generally vary from about $10 \%$ to $50 \%$ of the response obtained due to total wave forces.

8. The response of the buoy is generally governed by wave forces. 
$\mathrm{E}_{17}=-\frac{5}{16} c_{5} A_{1}^{4} A_{3} \sin (4 \phi-\alpha)$

$\mathrm{E}_{18}=-\frac{15}{8} c_{5} A_{1}^{2} A_{3}^{3}(\sin \alpha \cos 2 \phi+\cos \alpha \sin 2 \phi)$

$\mathrm{E}_{19}=-\frac{15}{8} c_{5} A_{1} A_{3}^{4} \cos \phi$

(iii) Equating $\cos 3 \omega t$ terms equal to zero,

$E_{21}+E_{22}+E_{23}+E_{24}+E_{25}+E_{26}=0$

where $\mathrm{E}_{21}=-9 \omega^{2} A_{3} \cos \alpha-3 \delta \omega A_{3} \sin \alpha+c_{1} A_{3} \cos \alpha+\frac{c_{3}}{4} A_{1}^{3} \cos 3 \phi$

$\mathrm{E}_{22}=\frac{3}{4} c_{3} A_{3} \cos \alpha\left(2 A_{1}^{2}+A_{3}^{2}\right)$

$\mathrm{E}_{23}=\frac{5}{16} c_{5} A_{1}^{4}\left(A_{1} \cos 3 \phi+2 A_{3} \cos \alpha\right)$

$\mathrm{E}_{24}=\frac{5}{8} c_{5} A_{1}^{3} A_{3}^{2}\{\cos 3 \phi(2+\cos 2 \alpha)+\sin 2 \alpha \sin 3 \phi\}$

$\mathrm{E}_{25}=\frac{15}{4} c_{5} A_{1}^{2} A_{3}^{3} \cos \alpha$

$\mathrm{E}_{26}=\frac{5}{8} c_{5} A_{3}^{5} \cos \alpha$

(iv) Equating $\sin 3 \omega t$ terms equal to zero,

$E_{31}+E_{32}+E_{33}+E_{34}+E_{35}+E_{36}+E_{37}=0$

Where $\mathrm{E}_{31}=9 \omega^{2} A_{3} \sin \alpha-3 \delta \omega A_{3} \cos \alpha-c_{1} A_{3} \sin \alpha$

$\mathrm{E}_{32}=-\frac{c_{3}}{4} A_{1}^{3} \sin 3 \phi$

$\mathrm{E}_{33}=-\frac{3}{4} c_{3} A_{3} \sin \alpha\left(2 A_{1}^{2}+A_{3}^{2}\right)$

$\mathrm{E}_{34}=-\frac{5}{16} c_{5} A_{1}^{4}\left(A_{1} \sin 3 \phi+6 A_{3} \sin \alpha\right)$

$\mathrm{E}_{35}=-\frac{5}{8} c_{5} A_{1}^{3} A_{3}^{2}\{\sin 3 \phi(2+\cos 2 \alpha)+\sin 2 \alpha \cos 3 \phi\}$

$\mathrm{E}_{36}=-\frac{15}{4} c_{5} A_{1}^{2} A_{3}^{3} \sin \alpha$

$\mathrm{E}_{37}=-\frac{5}{8} c_{5} A_{3}^{5} \sin \alpha$ 


\section{APPENDIX - II}

\section{Derivation of the Stability (Frequency) Bounds}

Hill's equation is given by

$$
\ddot{\varepsilon}+\lambda \dot{\varepsilon}+\alpha H[(\theta(t)] \varepsilon=0
$$

where $H\left[(\theta(t)]=\frac{a_{0}}{2}+\sum_{n} a_{n} \cos n \theta\right.$ and $\theta(t)=\omega t+\Phi$

Let the particular solution of Eq. (83) be

$$
\begin{aligned}
& \varepsilon=e^{\sigma t} Z(t) \\
& \dot{\varepsilon}=\sigma e^{\sigma t} Z(t)+e^{\sigma t} \dot{Z}(t) \\
& \ddot{\varepsilon}=\sigma^{2} e^{\sigma t} Z(t)+2 \sigma e^{\sigma t} \dot{Z}(t)+e^{\sigma t} \ddot{Z}(t)
\end{aligned}
$$

where $\dot{\varepsilon}$ represents differentiation with respect to $t$.

After substitution, Eq. (83) becomes

$$
\left[\ddot{Z}(t)+(2 \sigma+\lambda) \dot{Z}(t)+\left\{\left(\sigma^{2}+\lambda \sigma+\alpha H(\theta)\right\} Z(t)\right] e^{\sigma t}=0\right.
$$

where $\alpha H(\theta)=\alpha\left[\frac{a_{0}}{2}+2 \sum_{k} \frac{a_{k}}{2} \cos k \theta\right]$

$\ddot{x}_{0}(t)-f_{1} \sin \theta+\lambda \dot{x}_{0}+r\left(x_{0}\right)+\ddot{\varepsilon}+\lambda \dot{\varepsilon}+\mathrm{c}_{1} \varepsilon+\mathrm{c}_{3} \varepsilon^{3}+3 \mathrm{c}_{3} x_{0}^{2} \varepsilon+3 \mathrm{c}_{3} x_{0} \varepsilon^{2}+\mathrm{c}_{5} \varepsilon^{5}+\quad ; \frac{\alpha a_{0}}{2}=\theta_{0}^{\prime} ; \quad \sigma^{2}+\lambda \sigma=\sigma^{\prime \prime 2}$
$5 \mathrm{c}_{5} x_{0}^{4} \varepsilon+10 \mathrm{c}_{5} x_{0}^{3} \varepsilon^{2}+10 \mathrm{c}_{5} x_{0}^{2} \varepsilon^{3}+5 \mathrm{c}_{5} x_{0} \varepsilon^{4}=0$ and $\frac{\alpha a_{k}}{2}=\theta_{k}^{\prime}$

Substitution of the above values in Eq. (87) leads to

$$
\ddot{Z}(t)+2 \sigma^{\prime} \dot{Z}(t)+\left\{\sigma^{\prime \prime 2}+\theta_{0}^{\prime}+2 \sum_{k} \theta_{k}^{\prime} \cos k(\omega t+\phi)\right\} Z(t)=0
$$

From Eqs. (84) to (86), it is obvious that $\varepsilon$ remains stable if it is bounded as $t \rightarrow \infty$ and unstable if it grows unboundedly as $t \rightarrow \infty$. The solution is neutral if it is periodic in $\pi$ or $2 \pi$. There will be several unstable regimes. For $n^{\text {th }}$ unstable regime, the solution can be written as

$$
\begin{aligned}
& =\frac{\omega n}{2} \cos \left(\frac{\omega n t}{2}+\phi\right) \cos \psi+\frac{\omega n}{2} \sin \left(\frac{\omega n t}{2}+\phi\right) \sin \psi \quad n=1,2 \ldots \ldots \\
& =\sin \left(\frac{\omega n t}{2}+\phi\right) \cos \psi-\cos \left(\frac{\omega n t}{2}+\phi\right) \sin \psi \\
& \dot{Z}(t)=\frac{\omega n}{2} \cos \left(\frac{\omega n t}{2}+\phi-\psi\right) \\
& =\frac{\omega n}{2} \cos \left(\frac{\omega n t}{2}+\phi\right) \cos \psi+\frac{\omega n}{2} \sin \left(\frac{\omega n t}{2}+\phi\right) \sin \psi \\
& \ddot{Z}(t)=-\frac{\omega^{2} n^{2}}{4} \sin \left(\frac{\omega n t}{2}+\phi-\psi\right) \\
& =-\frac{\omega^{2} n^{2}}{4} \sin \left(\frac{\omega n t}{2}+\phi\right) \cos \psi+\frac{\omega^{2} n^{2}}{4} \cos \left(\frac{\omega n t}{2}+\phi\right) \sin \psi
\end{aligned}
$$

Substitution of the values of $Z(t), \dot{Z}(t)$ and $\ddot{Z}(t)$ in Eq. (90) leads to 
$-\frac{\omega^{2} n^{2}}{4} \sin \left(\frac{\omega n t}{2}+\phi\right) \cos \psi+\frac{\omega^{2} n^{2}}{4} \cos \left(\frac{\omega n t}{2}+\phi\right) \sin \psi+2 \sigma^{\prime} \frac{\omega n}{2} \cos \left(\frac{\omega n t}{2}+\phi\right) \cos \psi+$

$2 \sigma^{\prime} \frac{\omega n}{2} \sin \left(\frac{\omega n t}{2}+\phi\right) \sin \psi+\left\{{\sigma^{\prime \prime}}^{2}+\theta_{0}^{\prime}+2 \sum_{k} \theta_{k}^{\prime} \cos k(\omega t+\phi)\right\} \times\left\{\sin \left(\frac{\omega n t}{2}+\phi\right) \cos \psi-\right.$

$\left.\cos \left(\frac{\omega n t}{2}+\phi\right) \sin \psi\right\}=0$

Considering only values of $k=n=1$ in the series term of Eq. (94). It will give $2 T$ period doubled solution with $a_{0}$ and $a_{1}$ coefficients only.

$-\frac{\omega^{2}}{4} \sin \left(\frac{\omega t}{2}+\phi\right) \cos \psi+\frac{\omega^{2}}{4} \cos \left(\frac{\omega t}{2}+\phi\right) \sin \psi+\sigma^{\prime} \omega \cos \left(\frac{\omega t}{2}+\phi\right) \cos \psi+$

$\sigma^{\prime} \omega \sin \left(\frac{\omega t}{2}+\phi\right) \sin \psi+\left\{\sigma^{\prime \prime 2}+\theta_{0}^{\prime}+2 \theta_{1}^{\prime} \cos (\omega t+\phi)\right\} \times\left\{\sin \left(\frac{\omega t}{2}+\phi\right) \cos \psi-\right.$

$\left.\cos \left(\frac{\omega t}{2}+\phi\right) \sin \psi\right\}=0$

Separating out $\sin \left(\frac{\omega t}{2}+\phi\right)$ terms from Eq. (95) and equating to zero, leads to following equation

$\sigma^{\prime} \omega \sin \psi+\left(\sigma^{\prime \prime 2}+\theta_{0}^{\prime}-\frac{\omega^{2}}{4}\right) \cos \psi-\theta_{1}^{\prime} \cos \psi=0$

Separating out $\cos \left(\frac{\omega t}{2}+\phi\right)$ terms from Eq. (95) and equating to zero, leads to following equation

$\sigma^{\prime} \omega \cos \psi-\left(\sigma^{\prime \prime 2}+\theta_{0}^{\prime}-\frac{\omega^{2}}{4}\right) \sin \psi-\theta_{1}^{\prime} \sin \psi=0$

Multiplying Eqs. (96) and (97) by $\sin \psi$ and $\cos \psi$ respectively and adding

$\sigma^{\prime} \omega-2 \theta_{1}^{\prime} \sin \psi \cos \psi=0$

Therefore, $\sin 2 \psi=\frac{\sigma^{\prime} \omega}{\theta_{1}^{\prime}}$

and $\cos 2 \psi=\sqrt{1-\sin ^{2} 2 \psi}=\frac{\sqrt{\theta_{1}^{\prime 2}-\sigma^{\prime 2} \omega^{2}}}{\theta_{1}^{\prime}}$

Multiplying Eqs. (96) and (97) by $\cos \psi$ and $\sin \psi$ respectively and subtracting

$\left\{\sigma^{\prime \prime 2}+\theta_{0}^{\prime}-\frac{\omega^{2}}{4}\right)-\theta_{1}^{\prime}\left(\cos ^{2} \psi-\sin ^{2} \psi\right\}=0$

Therefore, $\quad \cos 2 \psi=\frac{\theta_{0}^{\prime}+{\sigma^{\prime \prime}}^{2}-\frac{\omega^{2}}{4}}{\theta_{1}^{\prime}}$

Equating Eqs. (100) and (102)

$\frac{\sqrt{\theta_{1}^{\prime 2}-\sigma^{\prime 2} \omega^{2}}}{\theta_{1}^{\prime}}=\frac{\theta_{0}^{\prime}+\sigma^{\prime \prime 2}-\frac{\omega^{2}}{4}}{\theta_{1}^{\prime}}$

Squaring both sides of Eq. (103)

$\left(\theta_{0}^{\prime}-\frac{\omega^{2}}{4}\right)^{2}+{\sigma^{\prime \prime}}^{4}-2{\sigma^{\prime \prime}}^{2}\left(\theta_{0}^{\prime}-\frac{\omega^{2}}{4}\right)={\theta_{1}^{\prime}}^{2}-{\sigma^{\prime}}^{2} \omega^{2}$

Simplifying Eq. (104) 


$$
\begin{aligned}
& \sigma^{\prime \prime}-2 \sigma^{\prime \prime}\left(\theta_{0}^{\prime}-\frac{\omega^{2}}{4}\right)+{\sigma^{\prime}}^{2} \omega^{2}-\theta_{1}^{2}+\left(\theta_{0}^{\prime}-\frac{\omega^{2}}{4}\right)^{2}=0 \\
& \text { or } \left.\sigma^{\prime \prime 2}=\left(\theta_{0}^{\prime}-\frac{\omega^{2}}{4}\right) \pm \sqrt{\left(\theta_{0}^{\prime}-\frac{\omega^{2}}{4}\right)^{2}-\left\{{\sigma^{\prime}}^{2} \omega^{2}-\theta_{1}^{\prime 2}+\left(\theta_{0}^{\prime}-\frac{\omega^{2}}{4}\right)^{2}\right.}\right\}
\end{aligned}
$$

For unstable condition $\sigma^{\prime \prime 2} \geq 0$

$\left.\left(\theta_{0}^{\prime}-\frac{\omega^{2}}{4}\right) \pm \sqrt{\left(\theta_{0}^{\prime}-\frac{\omega^{2}}{4}\right)^{2}-\left\{\sigma^{\prime 2} \omega^{2}-\theta_{1}^{\prime 2}+\left(\theta_{0}^{\prime}-\frac{\omega^{2}}{4}\right)^{2}\right.}\right\}=0$

Squaring and simplifying Eq. (107)

$$
\theta_{0}^{\prime 2}+\frac{\omega^{4}}{16}-\frac{\theta_{0}^{\prime} \omega^{2}}{2}=-\sigma^{\prime 2} \omega^{2}+\theta_{1}^{\prime 2}
$$

Since at the unstable regime, $\sigma=0$, therefore by Eq. (89), $\sigma^{\prime}=\frac{\lambda}{2}$

Substituting the value of $\sigma^{\prime}$ in Eq. (108), it becomes

$$
\omega^{4}-4 \omega^{2}\left(2 \theta_{0}^{\prime}-\lambda^{2}\right)+16 \theta_{0}^{\prime 2}-16 \theta_{1}^{\prime 2}=0
$$

Solution of the quadratic equation in $\omega^{2}$ leads to

$$
\omega^{2}=\frac{4\left(2 \theta_{0}^{\prime}-\lambda^{2}\right) \pm 4 \sqrt{\left(2 \theta_{0}^{\prime}-\lambda^{2}\right)^{2}+4\left(\theta_{0}^{\prime 2}-\theta_{1}^{\prime 2}\right)}}{2}
$$

Substituting the values of $\theta_{0}^{\prime}$ and $\theta_{1}^{\prime}$ from Eq. (89)

$$
\omega^{2}=2\left[\left(\alpha a_{0}-\lambda^{2}\right) \pm \sqrt{\lambda^{4}-2 \alpha \lambda^{2} a_{0}+\alpha^{2} a_{1}^{2}}\right]
$$

\section{REFERENCES}

[1] Umar A, Suhail A, Datta T K. Stability analysis of a moored vessel. J Offshore Mech Arctic Eng Trans ASME 2004; 126 (2): 164-74.

[2] Umar A, Datta T K. Nonlinear response of a moored buoy. Ocean Eng 2003; 30: 1625-46.

[3] Gottlieb O, Yim SCS. Nonlinear oscillations, bifurcations and chaos in a multi-point mooring system with a geometric nonlinearity . Appl Ocean Res 1992; 14: 241-57.

[4] Shah AA, Umar A, Siddiqui NA. A methodology for assessing the reliability of taut and slack mooring systems against instability. Ocean Eng 2005; 32: 1216-34.

[5] Liu Y, Bergdahl L. Extreme mooring cable tensions due to wavefrequency excitations. Appl Ocean Res 1998; 20: 237-49.

[6] Kareem A, Li Y. Stochastic response of tension leg platforms to wind and wave fields. J Wind Eng Ind Aerodymamics 1990; 36: 915-26.
[7] Adrezin R, Bar-Avi P, Benaroya H. Dynamic response of compliant offshore structures-review. J Aerospace Eng 1996; 11431 .

[8] Skop RA. Mooring system: a state of the art review. J Offshore Mech Arctic Eng 1988; 110: 365-72.

[9] Oppenhiem BW, Wilson PA. Low frequency dynamics of moored vessels. Mar Technol 1982; 19(1): 1-22.

[10] Bisht RS, Jain AK. Second-order drift force response of offshore guyed towers. Ocean Eng 1995; 22: 251-70.

[11] Ahmad S, Islam NA, Ali A. Wind-induced response of tension leg platform. J Wind Eng Ind Aerodymamics 1997; 72: 225-40.

[12] Taylor RE., Hung SM. Second order diffraction forces on vertical cylinder in regular waves. Appl Ocean Res 1987; 9(1): 19-30.

[13] Ioos G, Josheph, DD. Elementary Stability and Bifurcation Theory, Springer-Verlag: New York 1981. 